This item was submitted to Loughborough's Research Repository by the author.

Items in Figshare are protected by copyright, with all rights reserved, unless otherwise indicated.

\title{
Modelling curved-layered printing paths for fabricating large-scale construction components
}

\section{PLEASE CITE THE PUBLISHED VERSION}

http://dx.doi.org/10.1016/j.addma.2016.06.004

\section{PUBLISHER}

(c) Elsevier

\section{VERSION}

AM (Accepted Manuscript)

\section{PUBLISHER STATEMENT}

This work is made available according to the conditions of the Creative Commons Attribution-NonCommercialNoDerivatives 4.0 International (CC BY-NC-ND 4.0) licence. Full details of this licence are available at: https://creativecommons.org/licenses/by-nc-nd/4.0/

\section{LICENCE}

CC BY-NC-ND 4.0

\section{REPOSITORY RECORD}

Lim, Sungwoo, Richard Buswell, Philip J. Valentine, Daniel Piker, Simon Austin, and Xavier De Kestelier. 2016. "Modelling Curved-layered Printing Paths for Fabricating Large-scale Construction Components". Loughborough University. https://hdl.handle.net/2134/21980. 


\title{
Modelling curved-layered printing paths for fabricating large- scale construction components
}

\author{
Sungwoo Lim ${ }^{1 \star}$ Richard A. Buswell ${ }^{2}$, Philip J. Valentine ${ }^{3}$, Daniel Piker ${ }^{4}$, Simon A. \\ Austin $^{5}$, Xavier De Kestelier ${ }^{6}$
}

${ }^{1}$ Department of Engineering and Innovation, Faculty of Mathematics, Computing and Technology, The Open University, Walton Hall, Milton Keynes, UK, MK7 6AA Email: sungwoo.lim@open.ac.uk, Tel: +44 (0) 1908 332126,

${ }^{2}$ Civil and Building Engineering, Loughborough University, Loughborough, UK, LE11 3TU. Email: r.a.buswell@lboro.ac.uk

${ }^{3}$ Bouygues, Elizabeth House, 39 York Road, London, UK, SEi 7NQ. Email: philip.valentine@bouygues-uk.com

${ }^{4}$ Foster + Partners, Riverside, 22 Hester Road, London, UK, SW11 4AN. Email: dpiker@fosterandpartners.com

${ }^{5}$ Civil and Building Engineering, Loughborough University, Loughborough, UK, LE11 3TU. Email: s.a.austin@lboro.ac.uk

${ }^{6}$ Foster + Partners, Riverside, 22 Hester Road, London, UK, SW11 4AN. Email: Xdekeste@fosterandpartners.com

* Corresponding author 


\title{
Modelling curved-layered printing paths for fabricating large- scale construction components
}

\begin{abstract}
In this paper, a non-conventional way of additive manufacturing, curved-layered printing, has been applied to large-scale construction process. Despite the number of research works on Curved Layered Fused Deposition Modelling (CLFDM) over the last decade, few practical applications have been reported. An alternative method adopting the CLFDM principle, that generates a curved-layered printing path, was developed using a single scripting environment called Grasshopper - a plugin of Rhinoceros ${ }^{\circledR}$. The method was evaluated with the 3D Concrete Printing process developed at Loughborough University. The evaluation of the method including the results of simulation and printing revealed three principal benefits compared with existing flat-layered printing paths, which are particularly beneficial to large-scale AM techniques: (i) better surface quality, (ii) shorter printing time and (iii) higher surface strengths.
\end{abstract}

Keywords: Curved-layered printing path, 3D concrete printing, digital fabrication, freeform construction, additive manufacturing, design automation

\section{Introduction}

Additive (a.k.a. rapid or layered) Manufacturing (AM) is now an integral part of modern product development [1], having been commercialised over the last three decades, particularly in the fields of aerospace, automotive manufacturing, medical applications [2], and the production of prototyping models for aesthetic and functional testing [3]. Recent research and practice such as Contour Crafting [4], D-shape [5] and 3D Concrete Printing (3DCP) [6] have all demonstrated the potential for largescale processes adopting $A M$ techniques as an alternative way of constructing building components. Conventional construction processes share the concept of mould-based shaping with manufacturing, and as a consequence AM processes also have advantages over conventional construction processes, including customisation without extra tools or moulds, the promise of design freedom, and functional integration [7, 8] with simple assembly.

Nowadays, architects increasingly express their concepts through unconventional geometries e.g. intricate freeform shapes such as Motor City at Aragon, Spain [9] and the UAE Pavilion at Shanghai Expo [10], and complex shaped building skins are realised with doubly-curved cladding panels. However, conventional construction methods, which mainly rely on moulds and formwork, have a limited capability, as they restrict the geometry that can be realised because of the limitations imposed by (i) casting angles, (ii) non-re-entrant shapes, and (iii) complexity [1]. Thus, AM processes are now a real alternative to conventional methods. A range of construction forms has been identified as possible applications where geometrical freedom has great potential for introducing mass customisation to the construction industry, replacing the need to minimise component variability to the limit of the number of moulds that can be economically produced. These include major urban developments in the Middle East, e.g. MASDAR city housing at Abu Dhabi [11], which would require an enormous number of detailed temporary formwork installations using conventional construction processes, to achieve the complex 
geometry envisaged for the building façade to control shading, solar gain and ventilation.

Despite the advantages of AM described above, however, AM also has some limitations such as a staircase effect, particularly when applied to large-scale production. Thus, the following research questions have emerged:

1) Is flat-layered printing an optimal method to print a complex geometric shape including freeform curvature, particularly with a lower resolution (i.e. a bigger FDM filament or thicker layers of SLA and SLS)?

2) What are the options for minimising the roughness on curved surfaces, created by a staircase effect from flat-layered printing paths?

3) How best can the roughness be minimised on curved surfaces as a preprocess (digitally designed printing path) rather than a post-process (surface finishing with grinding or rendering)?

\subsection{Flat-layered printing}

Flat-layered printing, which prints material on a two-dimensional plane layer by layer until it reaches the desired volume, is a typical AM process method. The flat-layered printing path has several familiar weaknesses. Firstly, in order to achieve the desired accuracy and resolution, particularly on curved surfaces, more layers are required within the same height [12]. However, this makes the printing process more timeconsuming, often reaching an unacceptable level. Secondly, the anisotropy property of the final component is another weakness, particularly with FDM $[13,14]$. Thirdly, it produces a staircase effect on the surface. Staircase effect occurs because of the geometric approximation of a curved surface profile using layers of uniform thickness [15]. The staircase effect is mainly related to the filament thickness, and it can be quantified by measuring the area or height of the cusp, which is the perpendicular length of the error triangle (Figure 1), where the cusp cannot exceed the filament thickness. Thus, it is obvious that more layers produce a reduced staircase effect. The third weakness is particularly noticeable with a large-scale AM component with lower resolution, i.e. larger filament size.

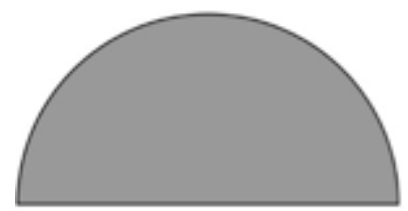

a) design

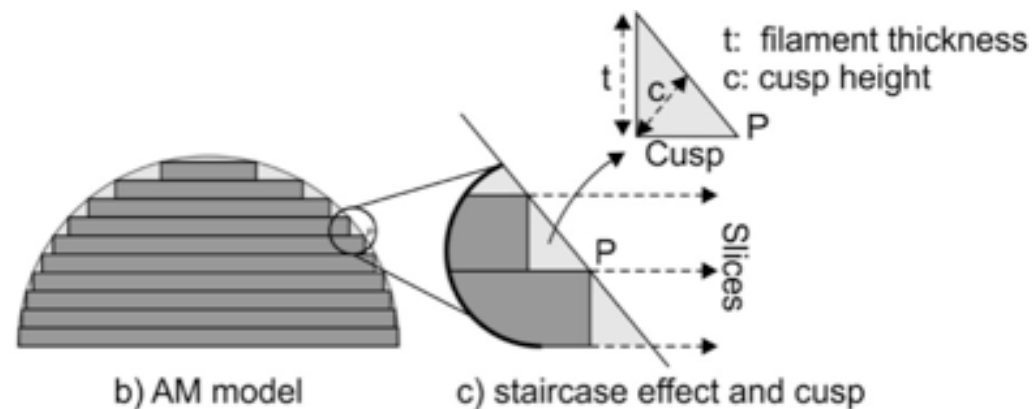

Figure 1: The error triangle and cusp height of staircase effect (where " $T$ " is the filament thickness and " $C$ " is the cusp height).

Existing construction works have investigated two methods to solve the issue. Dini [5] ground down the surface to a desired level of finish in a post-processing operation, and Khoshnevis [4] used a special towel to smoothen the surface as the build material is laid down. The former allows greater control of the final surface finish, but requires additional post-processing work and the inevitable implications of the dirty and dangerous working environment. Khoshnevis's approach eliminates the postprocessing to a great extent, although it is unlikely to render an internal surface to the degree of smoothness achievable using a conventional plastered finish. In essence, 
the surface finish requirements will tend to dictate the amount of extra work required. The key difference is whether a 'net-shape and grind' or an 'under-print and apply' approach is adopted. Crucially, of course, these need to be accounted for during the design and manufacture of the principle component so that parts can be manufactured within an acceptable tolerance.

\subsection{Curved-layered printing}

It is clear that using a pre-process to minimise the surface roughness would be preferable to post-processing, as it would eliminate extra work, e.g. grinding or plastering. The question is how to achieve it; one alternative is to improve printing paths.

Curved-layered printing seeks to improve the aesthetic and mechanical properties of FDM, by extending the flat-layered printing process from 2D to $3 \mathrm{D}$, thus material is printed on a non-planar layer. This means the printing nozzle should be positioned perpendicular to the target surface, regardless of the degree of curvature in order to deposit materials with a consistent angle, i.e. 90 degrees. In terms of the surface finishing of printed objects, the curved-layered method provides much less of a staircase effect compared with the conventional flat-layered method, because the material is deposited on the curved profile of the target surface. Consequently, it avoids the staircase effect at least for one direction (see Figure 2). It also minimises the potential peeling off of the layers because (i) the top surface is covered by a single layer rather than revealing multiple layer edges; and (ii) the total number of layers required for curved-layered printing is much less than for flat-layered. Thus, researchers [16-24] have attempted to minimise the problems of the conventional flat-layered printing with novel curved-layered printing methods.

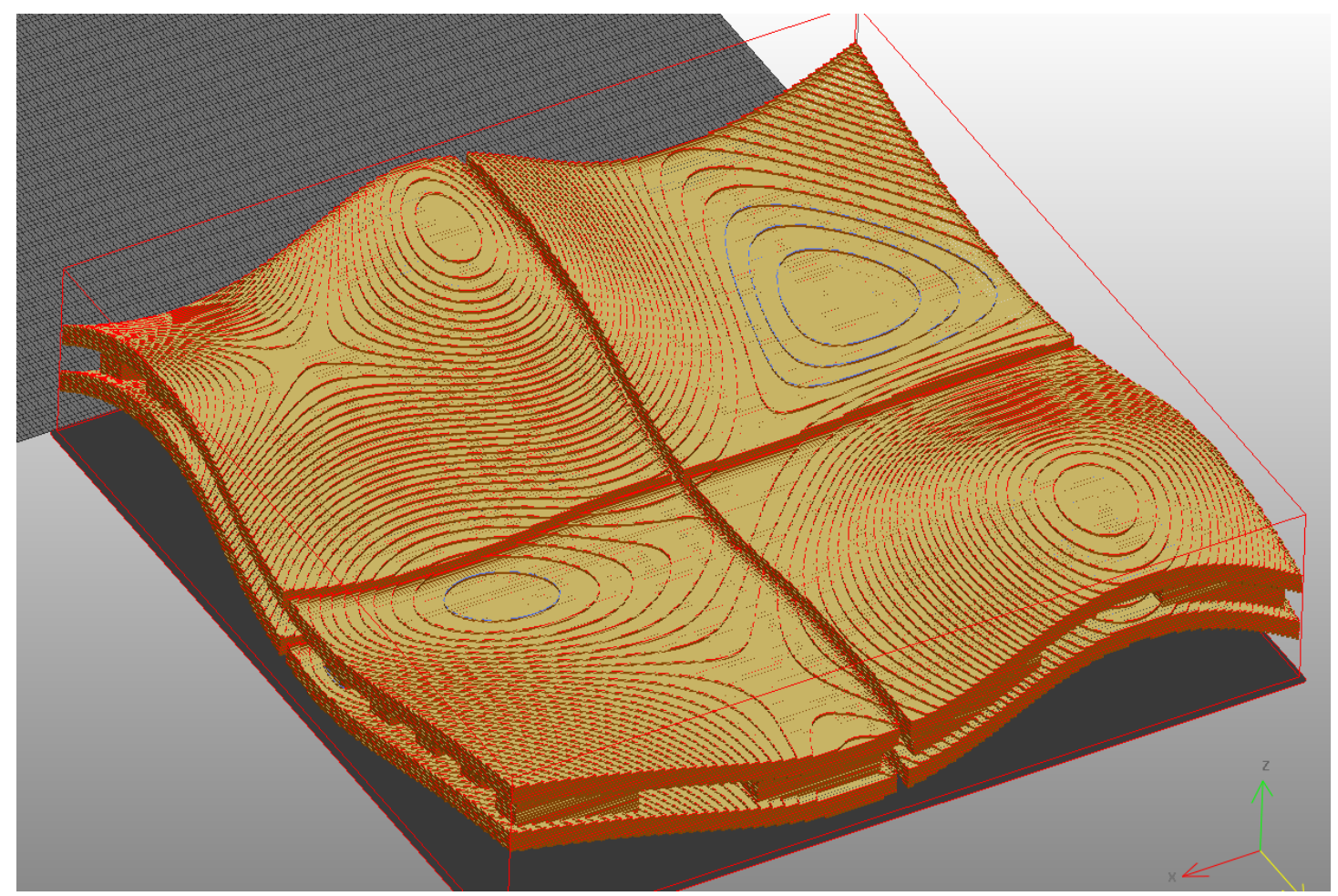

(a) Flat-layered paths generated from VisCAM RP 4.0. 


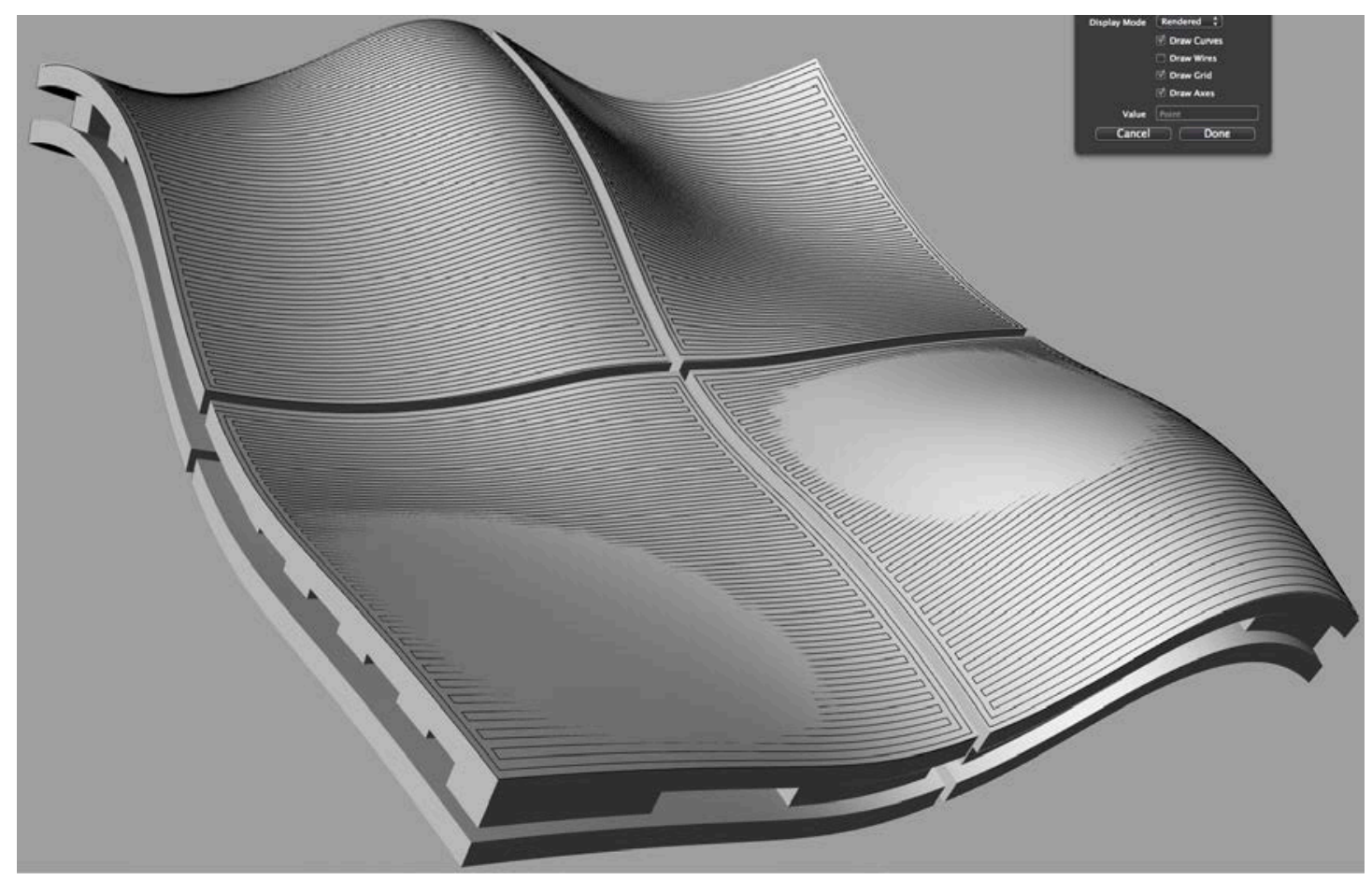

(b) Curved-layered path simulated using Rhinoceros 4.0.

Figure 2: Printing path comparison between a flat-layered and a curved-layered path on a doubly-curved sandwich panel design. The figure (b) clearly shows the curved-

layered paths have have no staircase effect in at least one direction.

Kalmanovich [16] introduced a curved-layered printing path against a conventional flat-layered path with the concept of a Height Grid which divides xy planes into an evenly-spaced grid, keeping the height (z) value as an element of this grid in order to represent the profile lines of curved layer. He also added the Open Loop method to the Height Grid method to adjust the curvature differences of each layer, which occurs by a normal (perpendicular) offset of curved-layers. This was necessary to approximate a new layer from a previous layer in terms of fitting a curved surface tangent. Klosterman [17] further developed the concept to achieve optimum mechanical performance of ceramics and fibre-reinforced composites by allowing their fibre continuity in a curved plane particularly in a surface area. Because Kalmanovich and Klosterman's work focused on a Laminated Object Manufacturing (LOM) process, they need a non-planar base to build a first layer. A critical issue with this approach is the potential problem of lateral bonding in curved-layered paths. Because of the irregularity of surface curvature, which creates curved layers, adjacent filaments do not necessarily lie on the same plane, which may introduce gaps between filaments. Later, researchers discussed how Curved-Layered Fused Deposition Modelling (CLFDM), using the superposition method, enables a higher strength than a flat-layer based FDM by applying longer length filaments, a larger contact area per layer and anisotropy between filaments [13, 25].

A decade later, Chakraborty [19] developed an algorithm to solve the bonding issue. To maintain uniform lateral bonding between filaments, Chakraborty suggested constant superposition with both the previous layer and the adjacent filaments. The problem with this approach is that the superposition of filaments would over-deposit a material and potentially disturbs the desired alignments of each filament, as the adjacent filament is not yet cured. This would particularly be a problem with a largescale construction application because the anticipated filament size is much bigger. For example, current works [4-6] use a filament thickness of $10 \sim 20 \mathrm{~mm}$, while a typical consumer FDM machine is less than $0.2 \mathrm{~mm}$ [26]. This means the amount of 
superposed construction applications materials would be at least 100 times greater than in other applications. The works on CLFDM (see Table 1) were demonstrated only with algorithms and/or simulation, and few applications using CLFDM have been reported yet. Thus Diegel [20] tried to apply CLFDM to produce plastic components with integral conductive tracks, which can be applied to the design of flat Printed Circuit Boards (PCBs) and/or electric transistors. He used a Four Vector Cross Product (FVCP) algorithm to generate offset layers; however, the initial result of his test printing shows imperfect offset layers possibly due to difficulty of material control. On the other hand, Allen [27] proposed a Curved Layer Fused Filament Fabrication (CLFFF) method. He applied a delta robot, which offers significant advantages over conventional Cartesian FDM systems by implementing identical speed and accuracy in all three axes. Allen split the CAD model into distinct parts to generate conventional printing paths for a core object, and CLFFF printing paths for a curvy skin, respectively. CLFFF involves a grid approach to generate $x$ and $y$ coordinates similar to Kalmanovich [16] and Klosterman [17] to generate a CLFF printing path. According to Allen's simulation, the proposed CLFFF method could reduce the printing time more than half of the convectional FDM method. Although the CLFFF method with the delta FFF system demonstrated effectiveness of method across varying topologies, the example components were chosen to be compatible with the specific printing path generation chosen.

Table 1: Existing research on curved-layer printing for additive manufacturing.

\begin{tabular}{|c|c|c|c|c|}
\hline Works & Year & Method & Filament path generation & $\begin{array}{c}\text { Application / } \\
\text { (material) }\end{array}$ \\
\hline [16] & 1997 & \multirow{2}{*}{$\begin{array}{l}\text { Height Grid }+ \\
\text { Open loop } \\
\text { Laminated } \\
\text { Object } \\
\text { Manufacturing } \\
\text { (LOM) }\end{array}$} & \multirow{2}{*}{$\begin{array}{l}\text { - Divide a xy-plane into an } \\
\text { evenly spaced grid and keep } \\
\text { the height (z) value as } \\
\text { elements of this grid } \\
\text { - Fitting a curved surface } \\
\text { tangent of an offset curved- } \\
\text { layer, taking a final z-height } \\
\text { value on that polynomial, and } \\
\text { apply it to the corresponding } \\
\text { location in the xy-plane }\end{array}$} & \multirow{2}{*}{$\begin{array}{l}\text { Net shape } \\
\text { fabrication } \\
\text { (Monolithic } \\
\text { ceramic / Ceramic } \\
\text { matrix composite) }\end{array}$} \\
\hline [17] & 1999 & & & \\
\hline [19] & 2008 & $\begin{array}{l}\text { Curved layer } \\
\text { Fused } \\
\text { Deposition } \\
\text { Modelling } \\
\text { (CLFDM) }\end{array}$ & $\begin{array}{l}\text { - Pre-specified superposition } \\
\text { through constant chord of } \\
\text { contact } \\
\text { - Filament cross-section on a } \\
\text { parametric surface } \\
\text { - Set an initial guess point } \\
\text { - Point correction by strength } \\
\text { requirement }\end{array}$ & $\begin{array}{c}\text { Biomedical } \\
\text { engineering } \\
\text { (Biocompatible } \\
\text { PMMA-resin) }\end{array}$ \\
\hline [20] & 2009 & $\begin{array}{l}\text { CLFDM with } \\
\text { triple-material } \\
\text { deposition head } \\
\text { (CLFDM) }\end{array}$ & $\begin{array}{l}\text { - Addition of z-coordinates for } \\
\text { each xy coordinate from } \\
\text { existing flat layers } \\
\text { - Separation of build and } \\
\text { support parts } \\
\text { - Four Vector Cross Product } \\
\text { (FVCP) algorithm for creation } \\
\text { of offset layers }\end{array}$ & $\begin{array}{c}\text { 3D PCBs } \\
\text { (ABS / Fab-epoxy } \\
\text { / conductive } \\
\text { polymer) }\end{array}$ \\
\hline [24] & 2015 & $\begin{array}{l}\text { Curved Layer } \\
\text { Adaptive Slicing } \\
\text { (CLAS) }\end{array}$ & $\begin{array}{l}\text { - Curved layer surface } \\
\text { generation through whole } \\
\text { facets offsetting } \\
\text { - Adaptive slicing algorithms } \\
\text { based on the cusp height and } \\
\text { residual height }\end{array}$ & $\begin{array}{l}\text { Laser engineered } \\
\text { net shaping } \\
\text { (FDM materials) }\end{array}$ \\
\hline
\end{tabular}




\begin{tabular}{|l|l|l|l|c|}
\hline [27] 2015 & $\begin{array}{l}\text { Curved Layer } \\
\text { Fused Filament } \\
\text { Fabrication } \\
\text { (CLFFF) }\end{array}$ & $\begin{array}{l}\text { - Incorporating with a delta style } \\
\text { robot } \\
\text { - Two sets of printing path: Skin } \\
\text { (CLFFF path) + Core } \\
\text { (conventional FDM path) } \\
\text { - Curved layer skin generation: } \\
\text { x, y coordinates from grid } \\
\text { surface, and z coordinate from } \\
\text { the surface equation }\end{array}$ & (Polyactide - PLA) \\
& & & \\
& & &
\end{tabular}

Despite the variety of approaches in existing methods (Table 1) they all adopt a single mathematical solution method. Thus, there will be always some exceptional cases where the algorithms cannot guarantee proper printing paths depends on the complexity of a target object. This paper investigates an alternative method for slicing layers and generating printing paths by using scripting languages, which can be adjusted interactively to fit various shapes. If successful, it could be more practical and efficient for practitioners. Two such experimental methods are evaluated. A comparison is also made between flat-layered and curved-layered printing paths with regard to: surface quality, the number of required layers and printing time, and surface strength.

\section{Method 1 - Printing path generation using Visual Basic scripts}

\subsection{The 3DCP production process and printing path generation}

The 3D Concrete Printing (3DCP) project was funded by the EPSRC through Loughborough University's Innovative Manufacturing and Construction Research Centre (IMCRC) with an award of $£ 1.2 \mathrm{~m}$ over a four-year period. The innovative 3DCP construction process has higher sustainability, adopting an extrusion-based Additive Manufacturing technique using conventional construction materials, including concrete [6]. The current resolution 3DCP can produce using a 3-axis gantry system (Figure 3 ) is between $10 \mathrm{~mm}$ (width) by $6 \mathrm{~mm}$ (thickness) and $25 \mathrm{~mm}$ by $15 \mathrm{~mm}$ filament size using different sizes of nozzles. During the project, a range of construction forms was identified where geometrical freedom has great potential for introducing mass customisation to the construction industry, replacing the need to minimise component variability to the limit of the number of moulds, which can be economically produced. These include complex shaped cladding panels and structures. The project was extended to explore commercial exploitation through an EPSRC Knowledge Transfer Account grant involving collaboration with Hyundai Engineering \& Construction and Foster+Partners. Our investigations concluded that a fully automated process, maximised printing quality, speed and size are crucial factors for commercial success.

Although 3DCP demonstrated its capability and potential in the construction area, it also inherits all the limitations of the flat-layered process, particularly the staircase effect. With 3DCP, the problem became more obvious because it uses a much bigger filament compared with general AM applications, as previously mentioned. Thus, the magnified staircase effect could cause some disadvantages, particularly (i) a disappointing aesthetic from an architectural design point of view; (ii) reducing surface strength on an inclined surface; and (iii) requiring greater tolerance for assembly. 


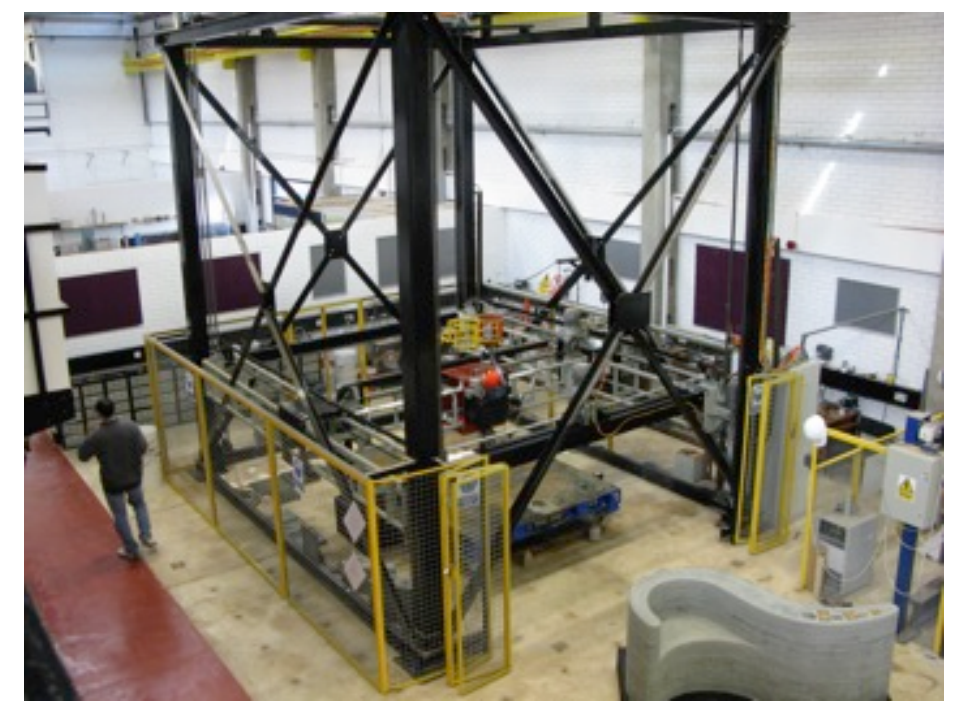

Figure 3: Three-axis gantry printing system of 3D Concrete Printing at Loughborough University $-5 \mathrm{~m}(\mathrm{~W}) \times 5 \mathrm{~m}(\mathrm{~L}) \times 6 \mathrm{~m}(\mathrm{H})$.

In order to minimise the potential issues addressed above, the CLFDM idea was applied to 3DCP to generate curved-layered printing paths of construction components with freeform shapes. Initially, a doubly-curved square panel was designed, and curved-layered printing paths were generated using the 3D modeler Rhinoceros [28] and Visual Basic scripts. Rhinoceros was used to split an imported design into thin layers, and to generate a desired path for each layer. In this paper, the generated path of the bottom layer is multiplied without normal (perpendicular) offset, and copied by the height of the filament to create multiple layers. This was done to keep the same curvature on both the inner and outer surfaces of the panel. Because all layers have an identical curvature, each layer will be mismatched with the next layer, either overlapped or not adjacent, depending on its curvature. Thus, the printing speed and flow-rate of the problem area are adjusted to compensate for the mismatched portion. In our initial experiment, slightly overlapped layers and paths are easier to fix the curvature (than a gap) while minimising potential voids. However, it required a bit of manual intervene during printing; thus we tested a different experiment with segmenting inner paths in our second method (Figure 12), and validated it with a real printing example (Figure 20).

A zigzag patterned printing path was created from the iso-curves on the surface, which are contour lines drawn using a set of 2D or 3D coordinates generated from the control points of each edge curve (Figure 4). The iso-curves were generated with a certain distance through a single direction, i.e. $x$ or $y$ axis, and were linked together to create a zigzag pattern. 3DCP uses generic GCode (CNC programming language) for the printing operation. Thus the coordinates of the generated printing paths are converted into a GCode format, and extra CNC-related commands, (nozzle on/off, pump start/stop, speed control of the pump and printing machine etc.) were added through a Visual Basic script to allow a quick turnaround of code and dynamic customisation of the process and output. At this stage, neither the Rhinoceros or Visual Basic scripts were integrated, so manual data transition was needed between them. 


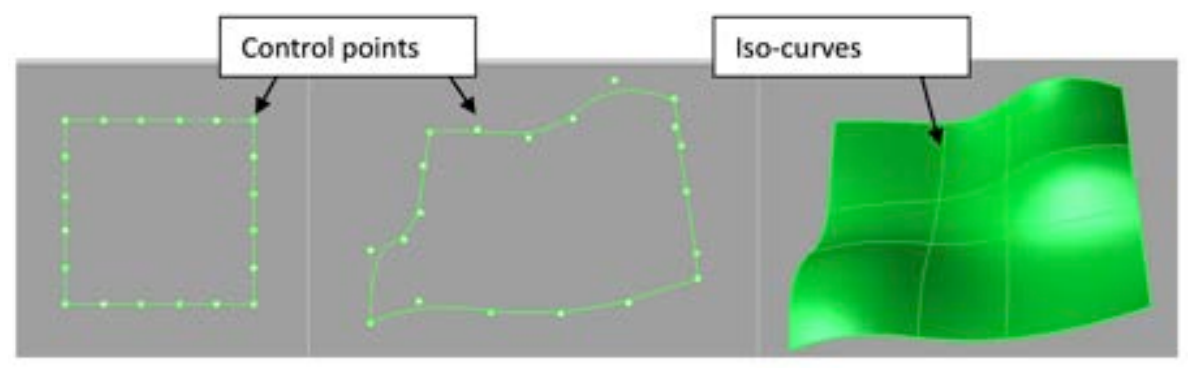

Figure 4: Iso-curve generation by the control points of edge curves.

This method was then tested with a real example - the world's first doubly-curved sandwich panel, $1.5 \mathrm{~m} \times 1.5 \mathrm{~m}$ in size, with internal conformal voids. The panel consists of top and bottom skins, each with $24 \mathrm{~mm}$ thickness, and both skins connected by 94 small pillars creating $52 \mathrm{~mm}$ depth of hollow (Figure 5 ). The panel design was chosen to demonstrate the degree of accuracy and complexity of the internal conformal voids that the curved-layered printing path could handle. The estimated weight of the panel was around $360 \mathrm{Kg}$ as the density of our concrete mix is about $2,300 \mathrm{Kg} / \mathrm{m}^{3}[14,29]$, which is too heavy for easy transport and installation. Thus, the design was split into four pieces, and an appropriate stand was also designed. Details of the load capacity of the panel are provided in Appendix 1.

This 3DCP system consists of a 3-axis gantry, which means the nozzle head cannot rotate according to the curvature. Thus the maximum angle we could print without collision between a deposited filament and the nozzle tip was 29 degrees in the $x$ direction and 27 degrees in the $y$ direction. The sandwich panel was designed within these limits. Nevertheless, this is a limitation of this particular 3DCP system but not of a curved-layered path in general. In principle, there should be no limitation in generating a curved-layered path if the printing system comprises more than 4 axes.
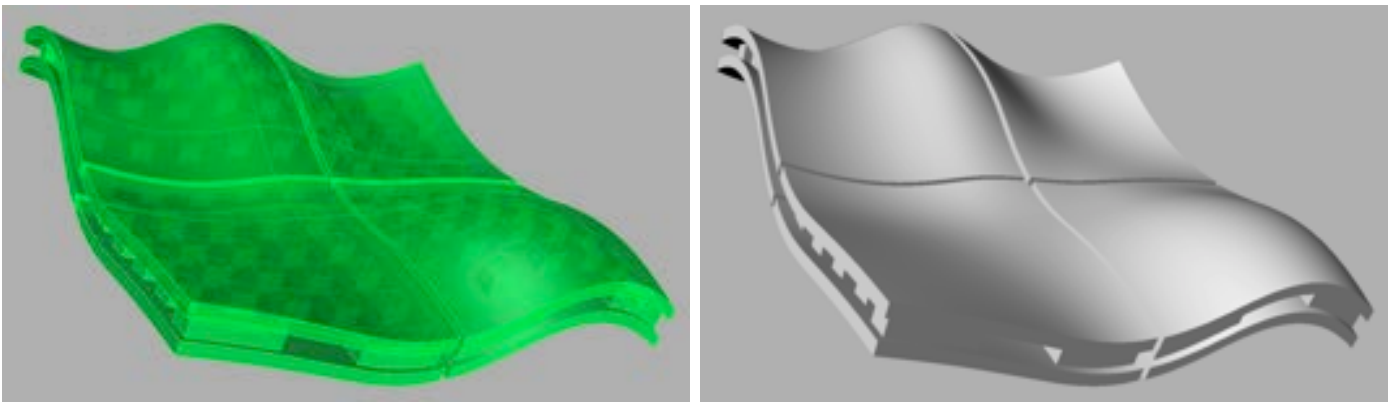

Figure 5: Ghosted (left) and rendered (right) images of the doubly-curved panel, which consisting of four small panels $(0.75 \mathrm{~m} \times 0.75 \mathrm{~m} \times 0.1 \mathrm{~m}$ each). The ghosted image shows the internal structure created by 94 pillars. The estimated weight of each panel piece was about $90 \mathrm{Kg}$.

The panels were printed using a two material approach as might be found in other additive manufacturing processes such as Fused Deposition Modelling. The component is manufactured by laying down either building or support material as required. The printing path of the base support material was generated using sequential flat-layers with the exception of the top layer (and all subsequent layers), which was generated with the curved-layered method described above. The lower flange was then deposited, followed by alternate depositions of build and support materials to create the pillars. Finally, the top flange of the sandwich panel was printed to complete the component. 


\subsection{Printing results with the Visual Basic scripts}

The printed panel was cured through consistently maintaining high humidity (90 $100 \%$ ) with wet hessian and plastic sheeting covers. The edges of each panel were trimmed for final joint after the curing. The printed panel demonstrated the natural surface finish produced with the curved-layered paths with no staircase effect at least for one direction; it was later exhibited in the Building Centre in London in August 2011, where it received wide interest from both the public and the built environment industry (Figure 6).
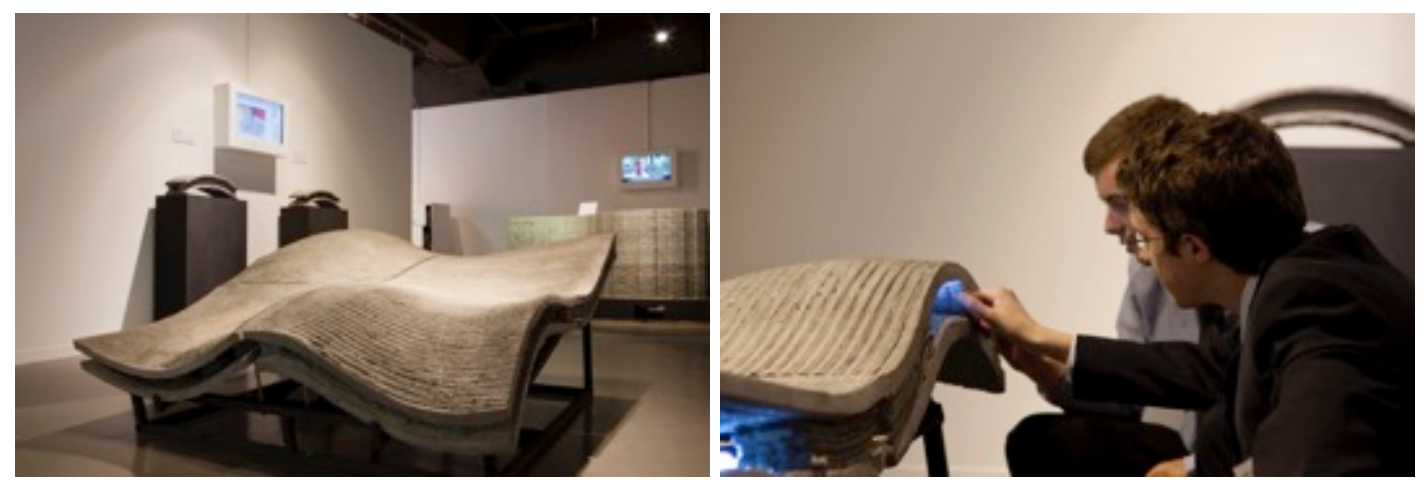

Figure 6: Printed doubly-curved 4-part sandwich panel $(1.5 \mathrm{~m} \times 1.5 \mathrm{~m} \times 0.1 \mathrm{~m})$. The panel was exhibited at the Building Centre Exhibition, $25^{\text {th }}$ August $-8^{\text {th }}$ September 2011 in London. (Photos: courtesy of Agnese Sanvito)

The tested method used Rhinoceros and Visual Basic, but the method uses two separate environments and requires manual data transition by layers and panels, making the path generation process far from straightforward. Thus, a second version of our method has since been developed.

\section{Method 2 - Printing path generation using the Grasshopper plugin of Rhinoceros}

Many researchers [30-32] believe that computational design requires a direct interaction between the architectural designer and the computer program, possibly through a scripting environment. Grasshopper [33], a plugin of Rhinoceros is a flexible parametric design tool that allows the creation of new algorithms or the modification of existing ones in a graphical scripting environment. It provides freedom and flexibility to designers, including those without programming or scripting knowledge, to apply new rules of behaviour and investigate design possibilities in specific problems under different architectural design conditions. Leading BIM companies like Autodesk [34] and individual Grasshopper developers [35] are holding discussions about how best BIM could be used for digital fabrication using Additive Manufacturing processes to support a seamless interoperable process between the design and manufacturing stages. Such a movement indicates Grasshopper's potential as a connector between AM and BIM. A designer can split such a model to simplify the path generation first, then the generator creates a predefined layer and printing path. Once the layers and paths are created, the designer can change a layer thickness and printing path according to the boundary conditions and geometric shape by simply adjusting parameters interactively using Grasshopper's graphical interface. Because its path generator does not rely on a single mathematical algorithm or solution, it has few limitations in terms of slicing and generating printing paths. 
The previous method using Rhinoceros and Visual Basic, i.e. the entire process from 3D modelling to printing path generation of a component, has been merged and reprogrammed in the Grasshopper. The current version of the Grasshopper definition produces two different printing paths: a zigzag path when the target surface consists of four boundary curves only, and a spinal path when the target surface is a nonrectangular shape. The tool also generates some extra variables, which may be changed from project to project or from model to model, including (i) the filament diameter, which is the dimensions of the extruded filament of materials, and (ii) the number of segments of surface area, which is determined by the amount of curvature of the model to minimise gaps in between the filaments. The following sequence explains the entire process of printing path generation using the Grasshopper definition.

\subsection{Input}

As an initial trial, a doubly-curved panel was deigned, consisting of four smaller panels without internal conformal voids (Figure 7), and its 3D B-rep (Boundary representation) model is prepared as an initial input. The panel was designed to be split into four $525 \mathrm{~mm}(\mathrm{~W}) \times 525 \mathrm{~mm}(\mathrm{~L}) \times 30 \mathrm{~mm}(\mathrm{H})$ panels, each with exactly the same geometry. One quadrant of the split surface is taken into the definition to create the printing paths of build parts. A build part path requires the bottom surface of the model to create the printing path, which is a starting layer of the additive printing process from the base upwards. To get a desired bottom surface of a panel the B-rep is exploded into its components, faces, edges and vertices. Once a bottom surface is retrieved from the list of faces, it is re-parameterized and modifies its matrix to be transposed. This creates another surface to be used in conjunction with the original to allow the cross-hatching of layers. Both the transposed and original surfaces undergo the same process of creating the tool paths.

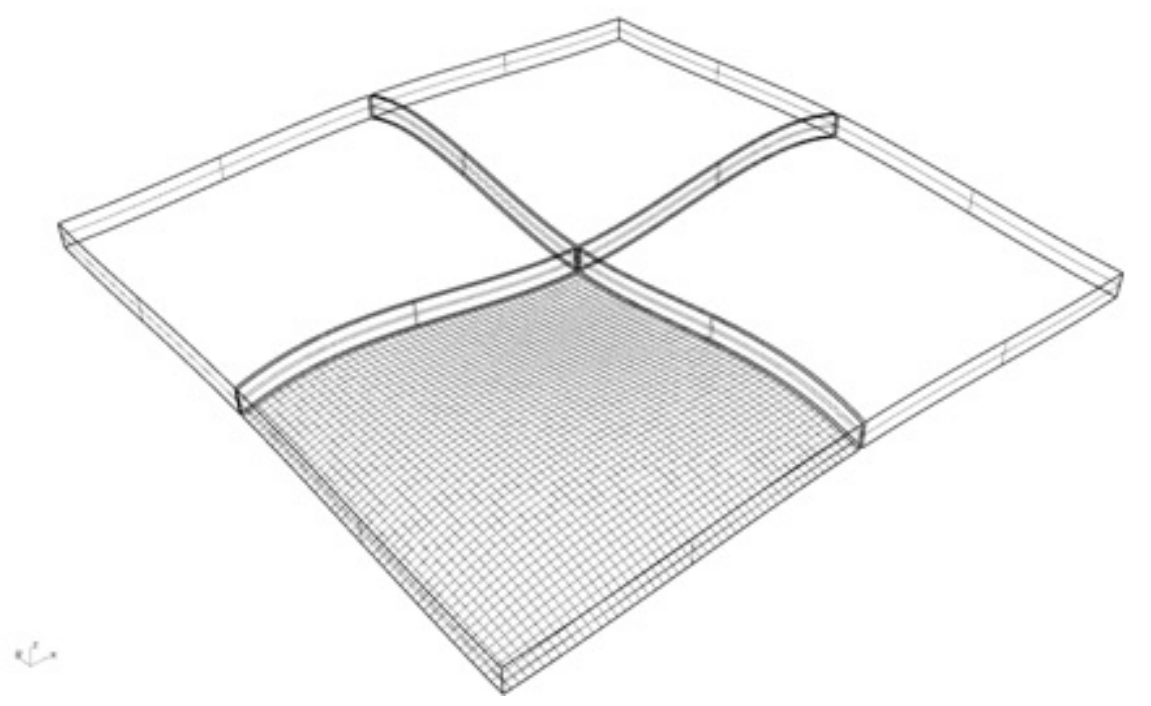

Figure 7: A doubly-curved panel design combined by four $525 \mathrm{~mm}(\mathrm{~W}) \times 525 \mathrm{~mm}(\mathrm{~L}) \times$ $30 \mathrm{~mm}(\mathrm{H})$ sub-panels.

\subsection{Build path creation}

Firstly, a bottom surface of the target object (Figure 8) is extracted and is split into the perimeter and the inner sub-surfaces. Then a perimeter surface is created by offsetting the edges of the bottom surface by two filaments width followed by a spinal perimeter path in it (Figure 9). In our experiment, a two filament width (20mm) was 
considered a minimum to resist horizontal deformation from the hydraulic pressure exerted by the inner path material. A perimeter path is needed to keep the surface resolution high, which minimises staircase effect, by retaining a smaller filament size regardless of the filament size of the interior path. In this case, the interior path could have a doubled depth of the perimeter path to increase the printing speed. The interior path is split into smaller segments, determined by the surface curvature. For now, the number of segments is determined by manual observation rather than automatic configuration, depending on the curvature of the panel. For example, if the panel is completely flat, only one segment is needed, while if the panel includes a radical curvature more segments are needed, since more gaps appear between the filaments. The segment shapes do not have to be an equal, rigid rectangle. If the curvature of a certain part of the panel were steep, the segment covering that area would be smaller in width to minimise the chance of gaps appearing. The UV parameters of the corners are found, and the closest untrimmed sub-surface to the offset is extracted by taking the average of the two ends. The edges of the subsurfaces are then joined and trimmed to create a spiral path. It was confirmed that between two to five perimeter paths would be enough to ensure strong bondage between the perimeter and the inner part from the previous printing test of the lifescale concrete bench $(1 \mathrm{~m}(\mathrm{~W}) \times 2 \mathrm{~m}(\mathrm{~L}) \times 0.8 \mathrm{~m}(\mathrm{H}))$ production [6].

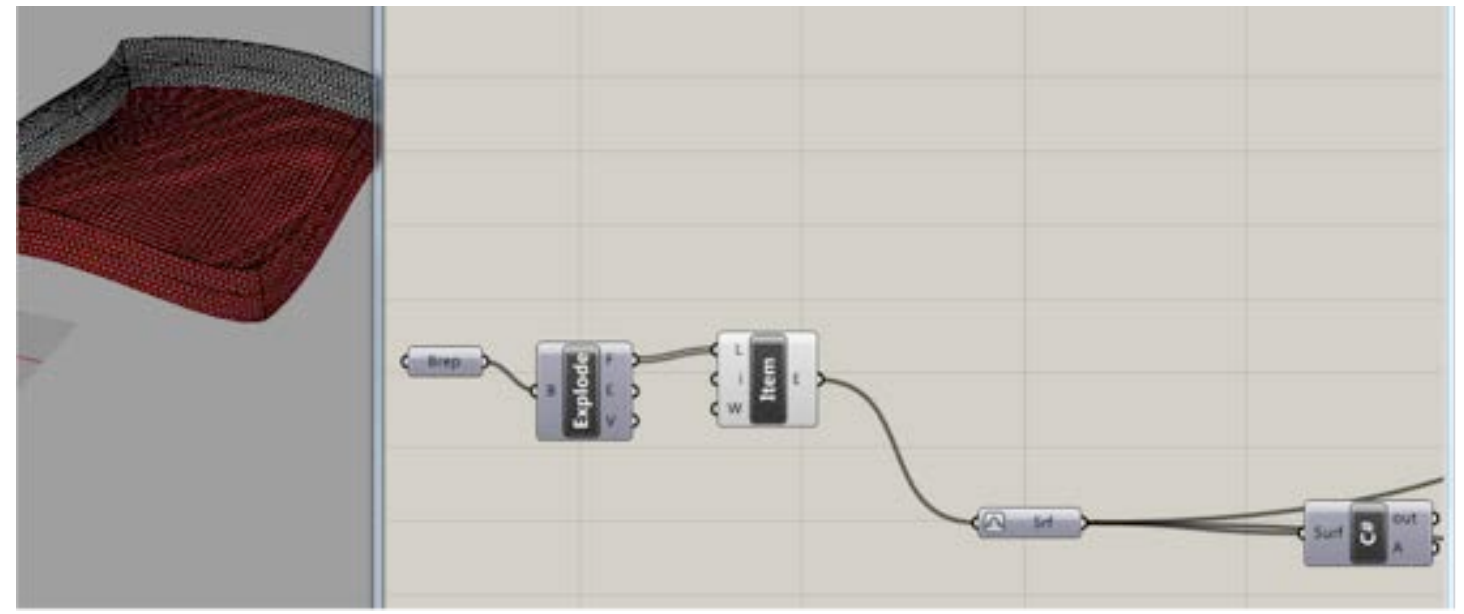

Figure 8: Extraction of the bottom surface of the target object.

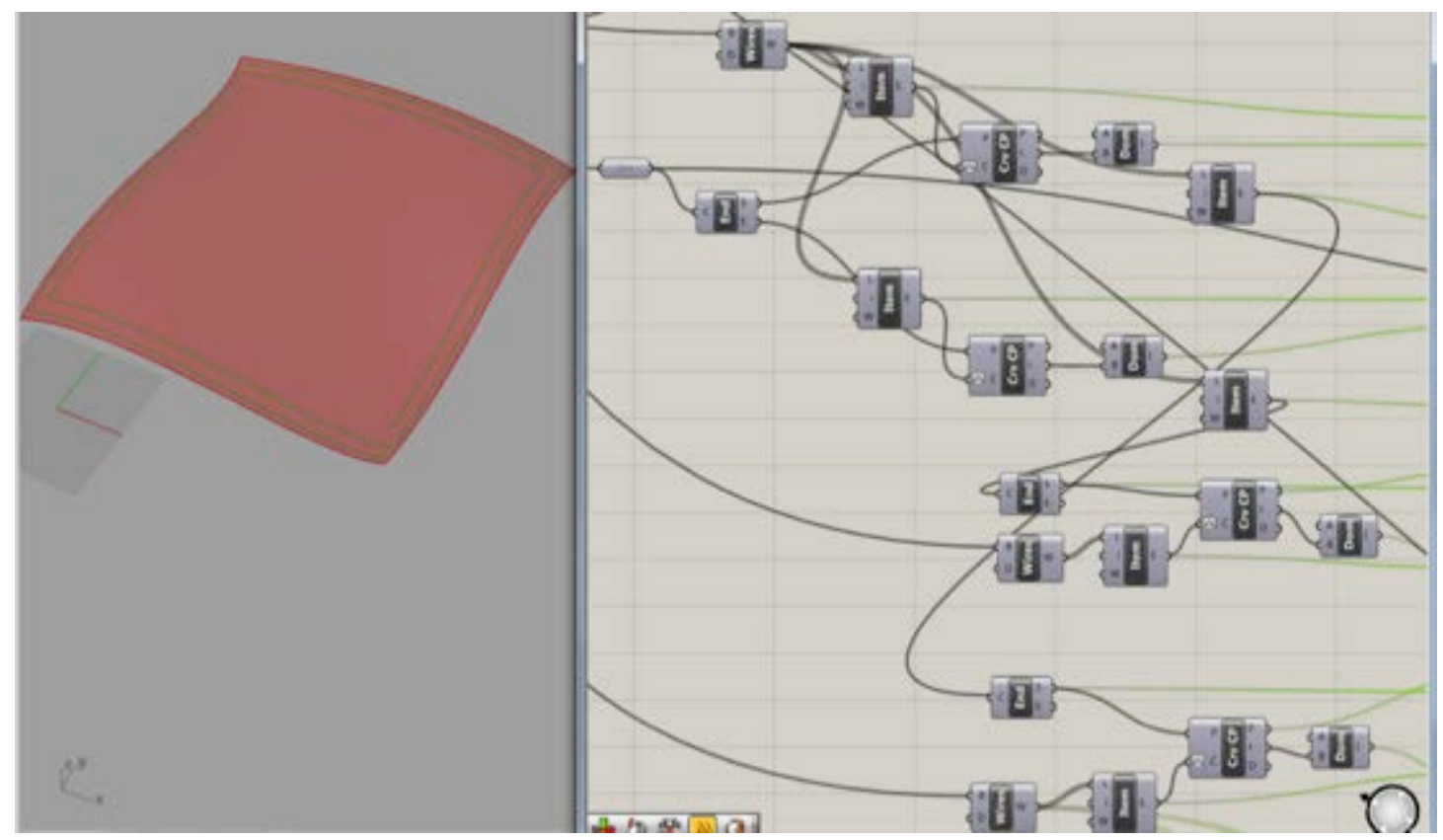


Figure 9: Creation of a perimeter path.

Secondly, the edges of each segment are extracted and offset on the surface, and the surface is split with the offset curves to create sub-surfaces, which are the desired inner path area (Figure 10). A zigzag path is then created, based on the filament width to be extruded. The perimeter path, segments and joining curves are joined to make one single poly-curve (Figure 11).

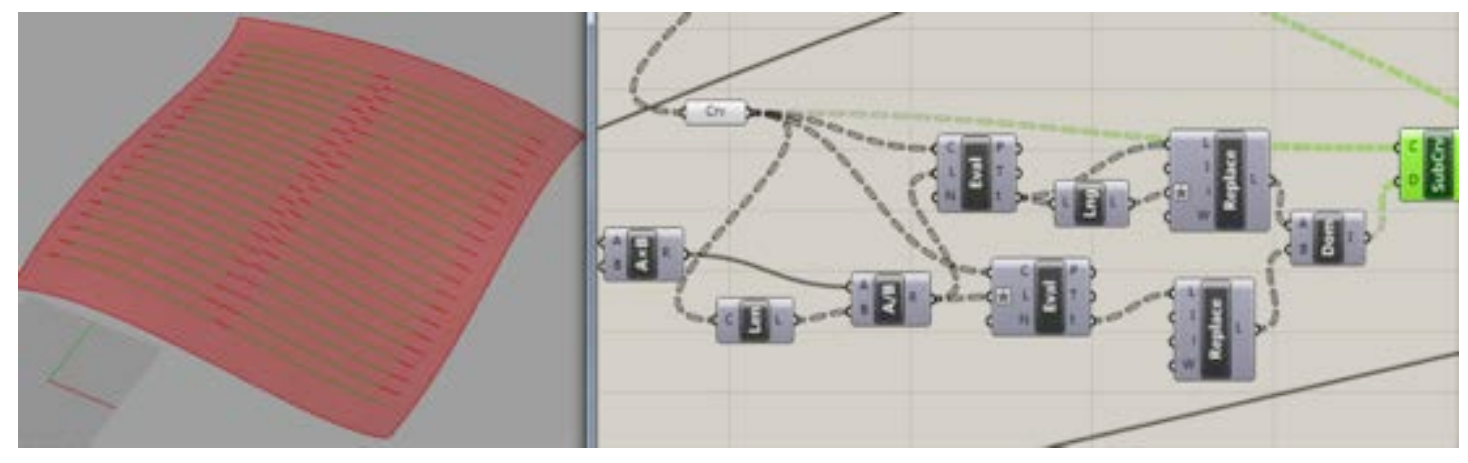

Figure 10: Creation of iso-curves.

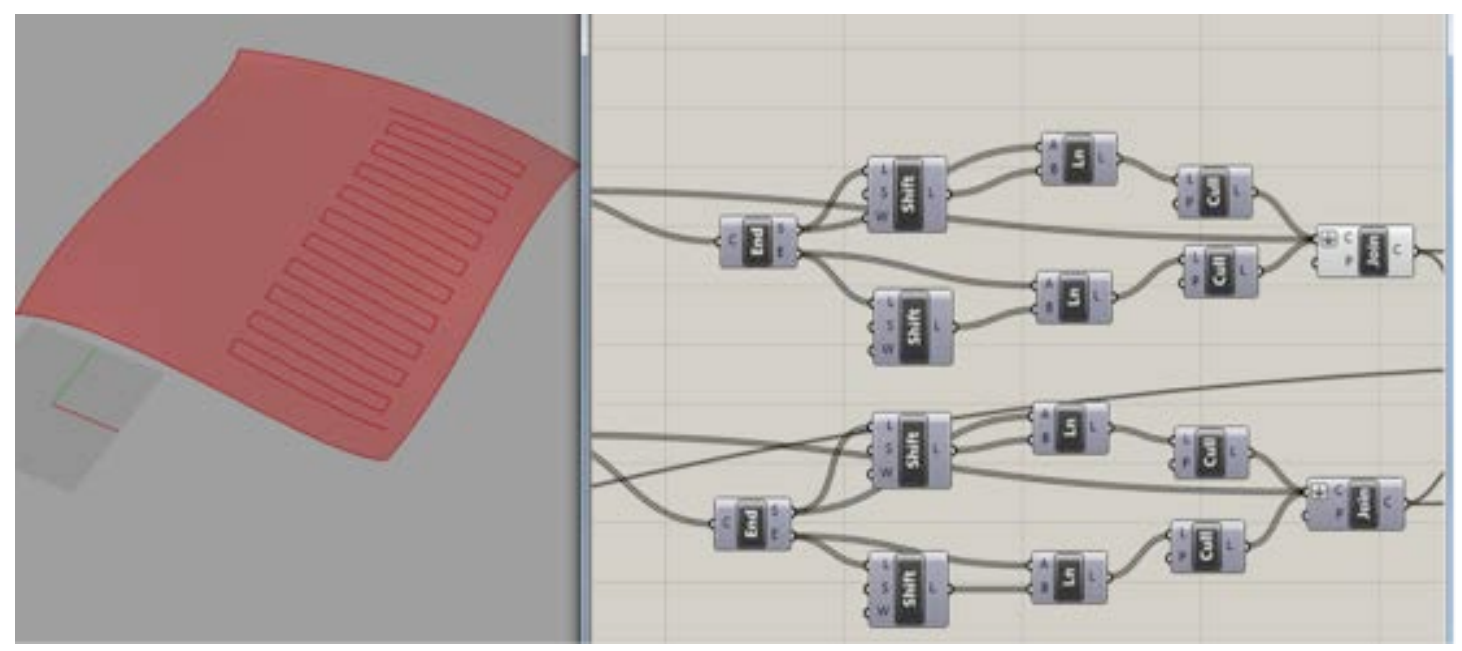

Figure 11: Creation of zigzag pattern by connecting the iso-curves.

There are several advantages to having segments for the inner path areas. Firstly, it minimises the gaps between filaments on a radical surface curvature as illustrated in Figure 12. Secondly, it gives an option to choose the direction of the path (either in $U$ or $\mathrm{V}$ direction) for each segment depending on the curvature. One potential drawback is that segments create more turning points in the path, causing more deposition of materials than a single straight line. However, this can be compensated for by adjusting the printing speed and flow-rate, as already mentioned.

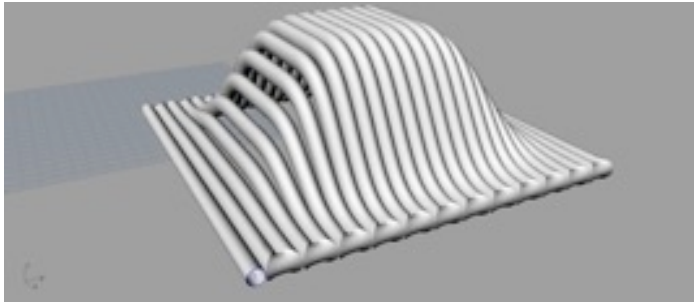

(a)

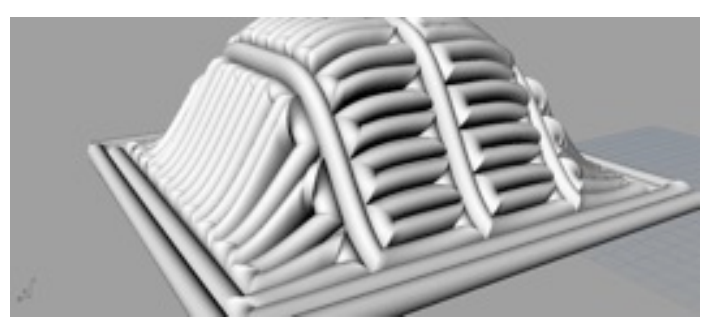

(b) 
Figure 12: Filament gaps on a radical surface curvature (a), and alternative path strategy by using smaller segments to minimise the gaps (b).

\subsection{Support part printing path}

In order to generate a support printing path, firstly a support volume is created by extruding the bottom surface of the B-Rep model of the build object to the negative $z$ direction, which covers the entire curvature of the bottom surface and the volume is trimmed to a flat base (Figure 13). A series of vector lines are created between the edge points for the first layer (Figure 14), then moving them in the $z$ direction to fill the boundary box (Figure 15). The lines are then trimmed by the support volume to cut any lines which go over the surface, before connecting them (Figure 16). Then the lines of each layer are connected to create a zigzag pattern (Figure 17 and Figure 18).

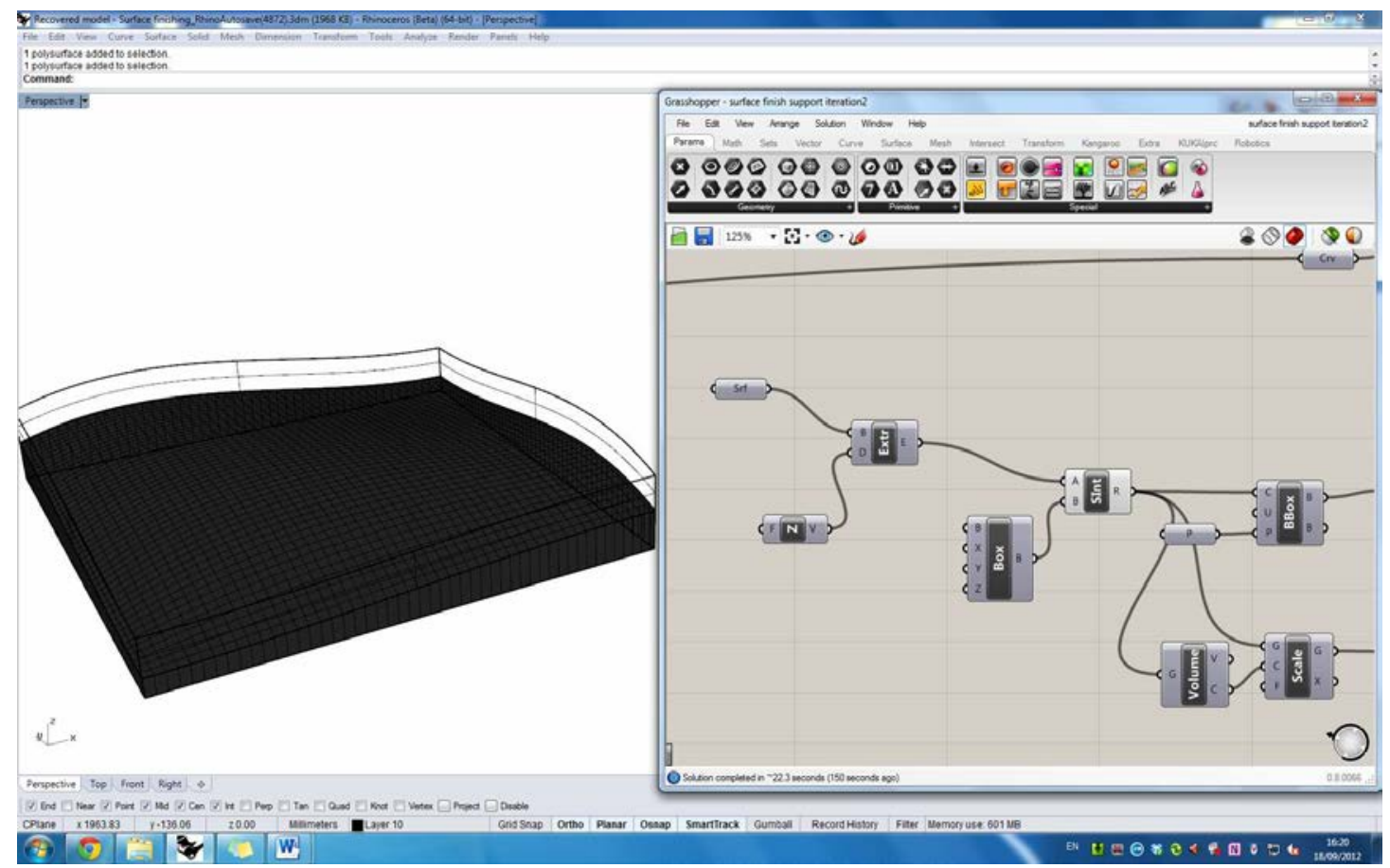

Figure 13: Creating a support volume. 


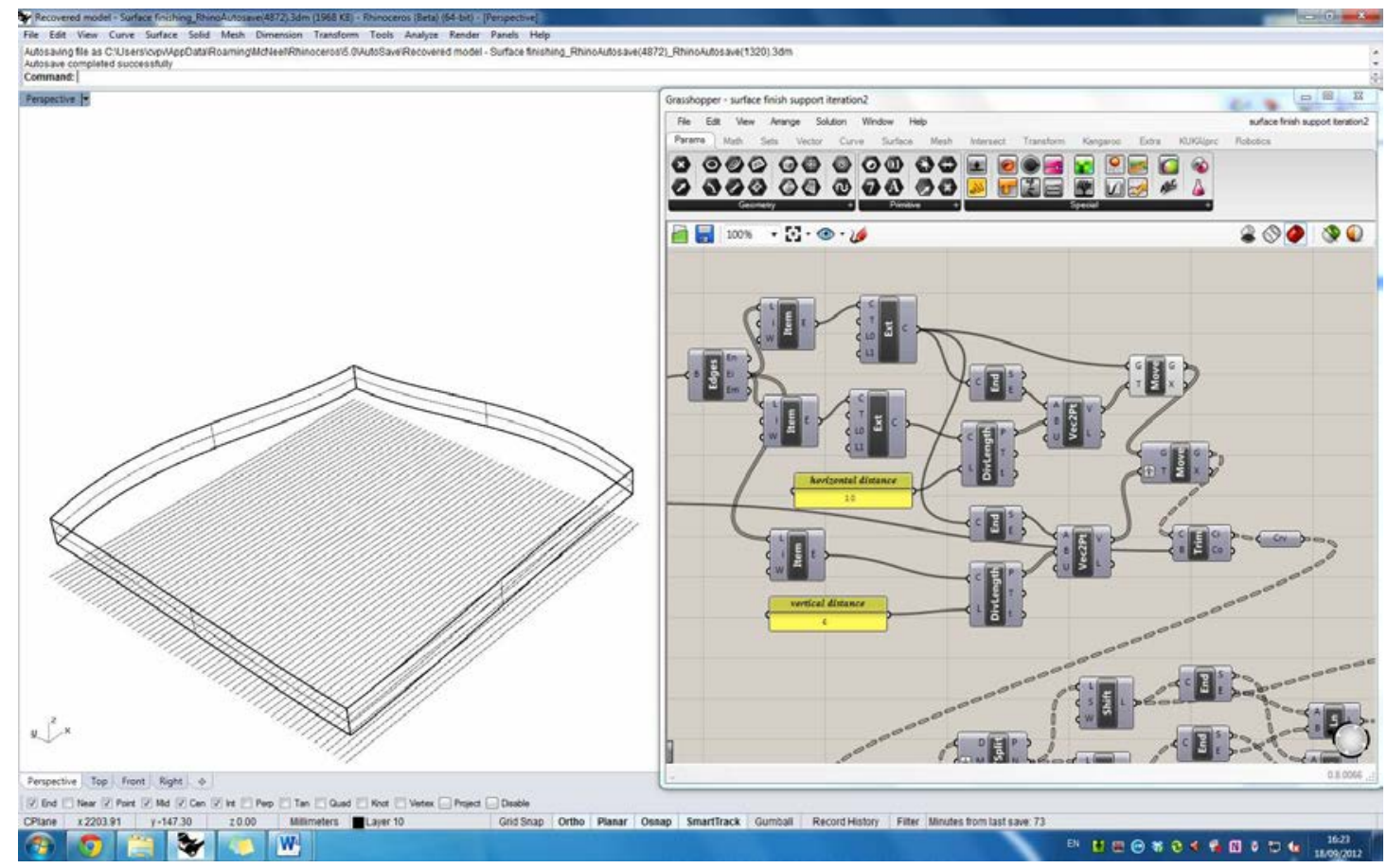

Figure 14: Creating baselines.

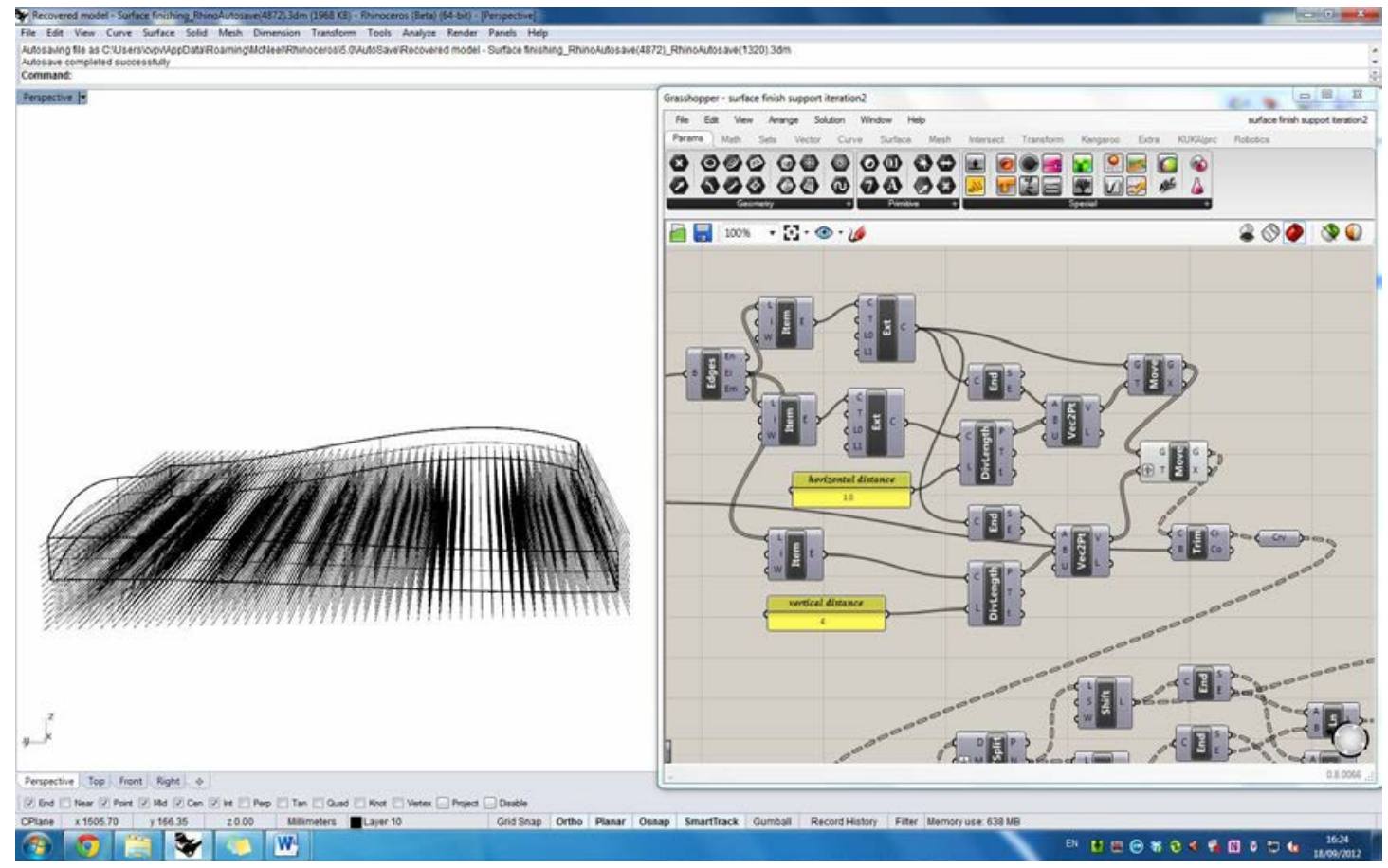

Figure 15: Duplicating the baseline for $z$ direction. 


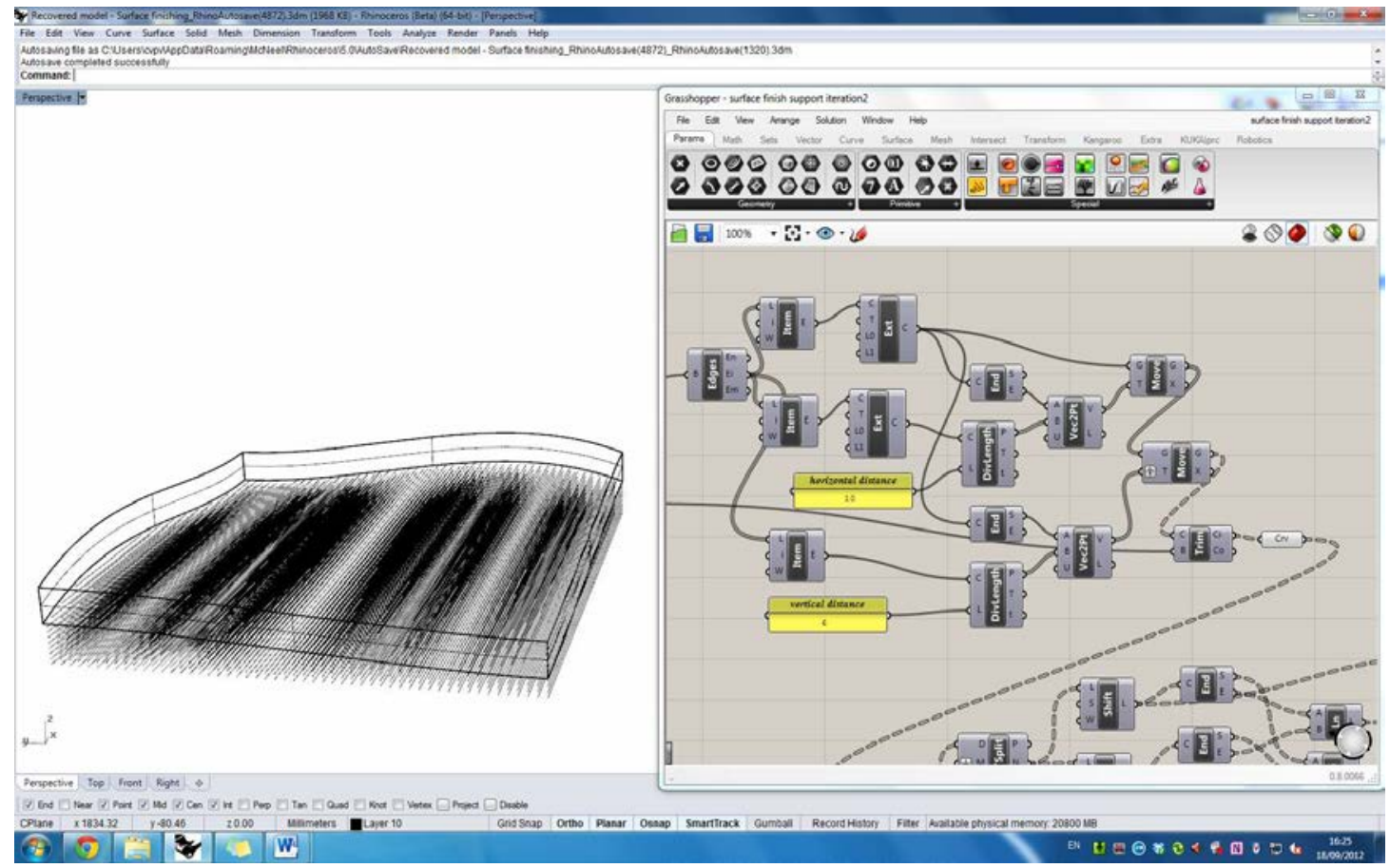

Figure 16: Trimming the baseline according to the base surface curvature.

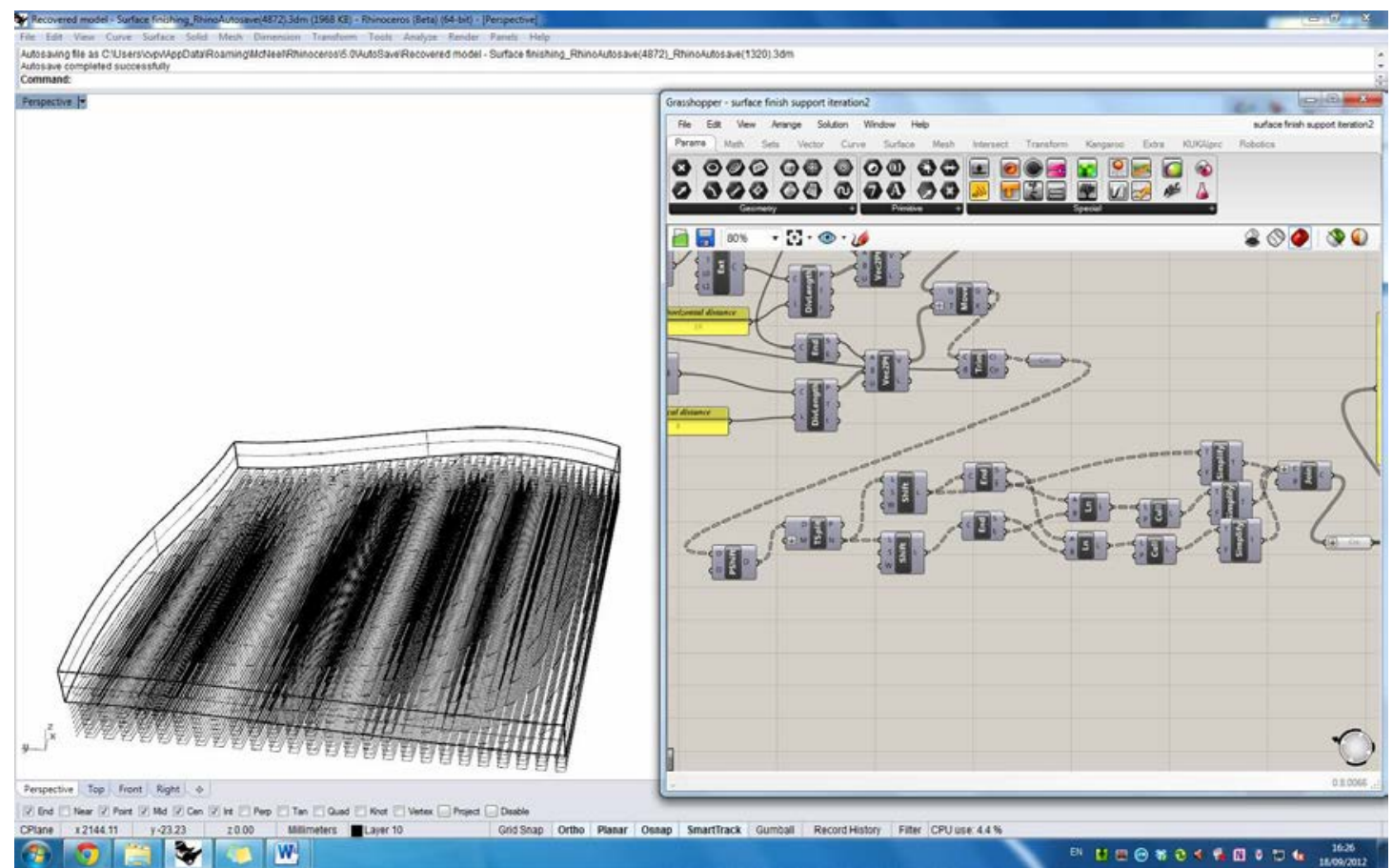

Figure 17: Creating zigzag lines by connecting the baselines. 


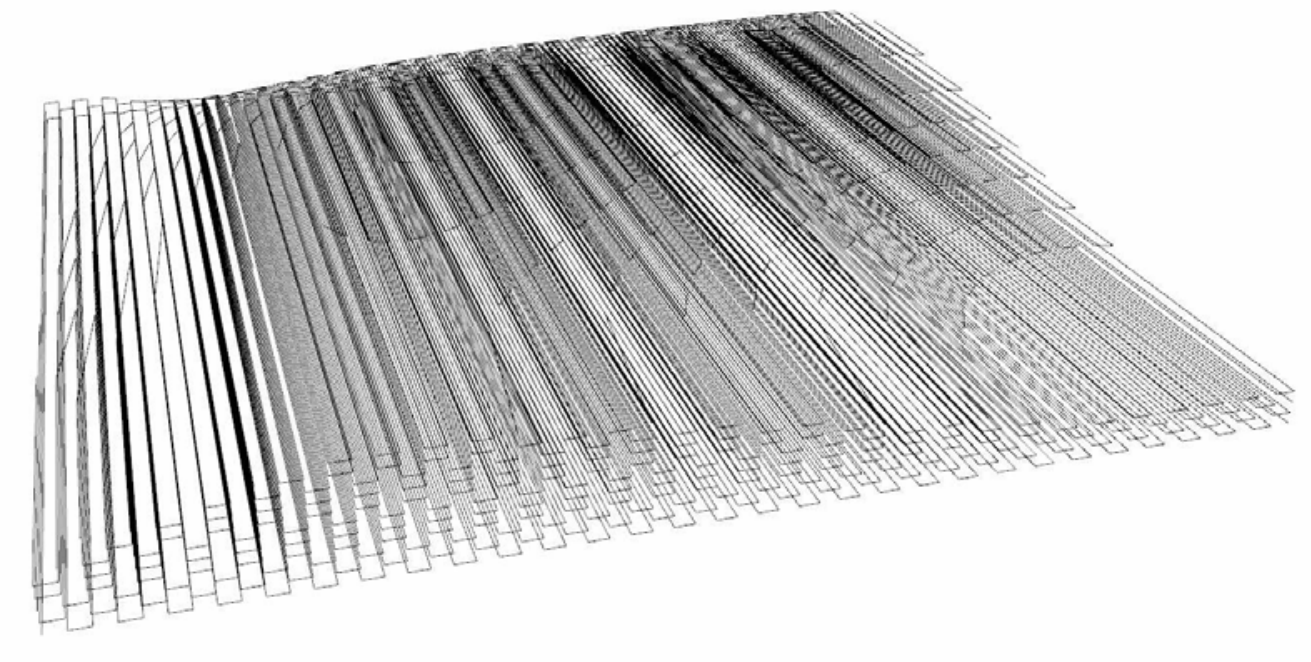

Figure 18: Completed printing path (zigzag) of the support part.

\subsection{GCode conversion}

Once the paths are created, it needs to be changed into a proper language, which can be used to control the printing system in use. The current version of the Grasshopper definition tweaked the existing Grasshopper definition called CAMel script [36], which produces 5-axis GCode, to produces 3-axis GCode to work with 3DCP system (Figure 19).

To turn the curved path data into GCode, the path is divided into a certain number of points, which determines the accuracy of the path. These points are evaluated on the surface to export the $x, y$ and $z$ values as well as the normal to the surface. With the values of $x, y, z$ and the normal, the first point is retrieved along with the length of the list to put the feed rate at the start of each line segment. The first point is decomposed to create the header of the code using functions to include the machine-specific commands needed in the start-up of the machine. A script is used to combine the point data, vectors from the normal, the feed rate, tip dimensions, and header and footer into the format of 3-axis GCode.

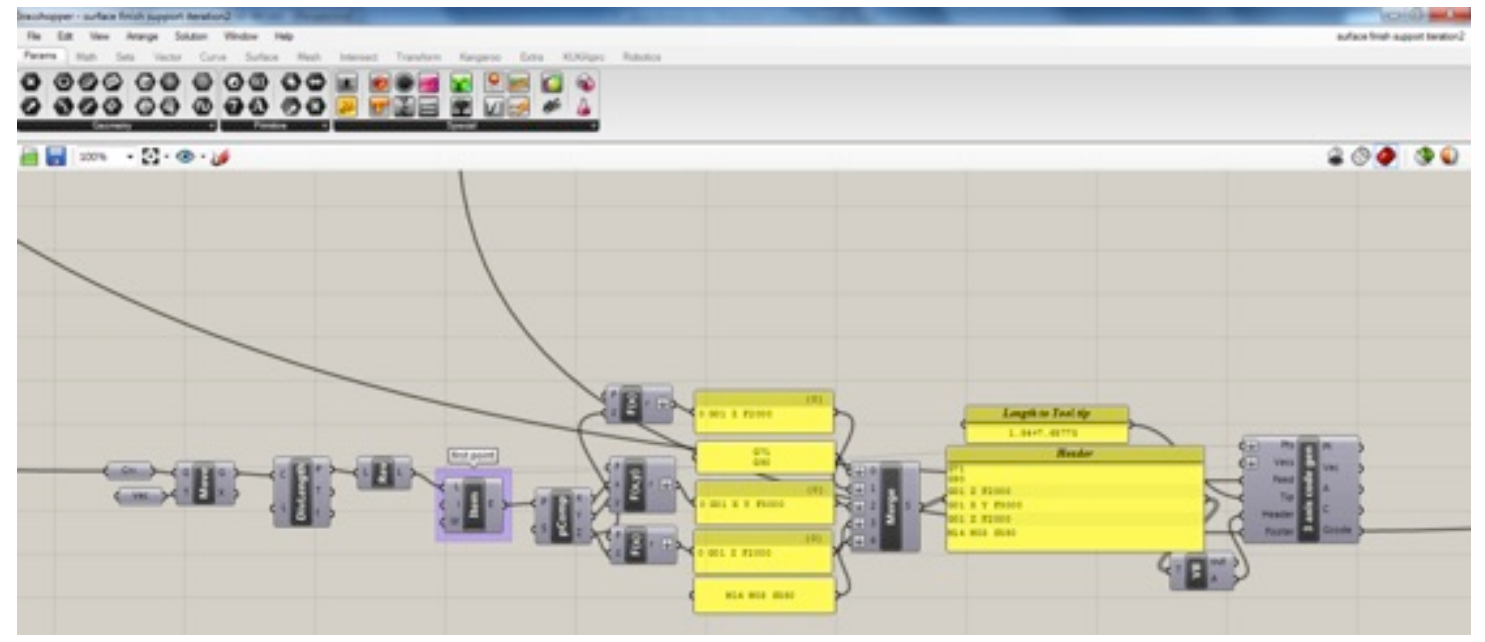

Figure 19: Definition of 3-axis code generation modified version of CAMel script [36]. 


\subsection{Printing results with the Grasshopper plug-ins}

With the generated GCode, another four doubly-curved panels were printed with different surface finishing and each trimmed to the desired $0.5 \mathrm{~m} \times 0.5 \mathrm{~m}$ size (see Figure 20). The natural surface finish produced with the curved-layered paths again shows minimal staircase effect, which is as smooth as other finishes, and provides unique aesthetics compared with other finishes, i.e. rendered with gypsum, patterned and ground.

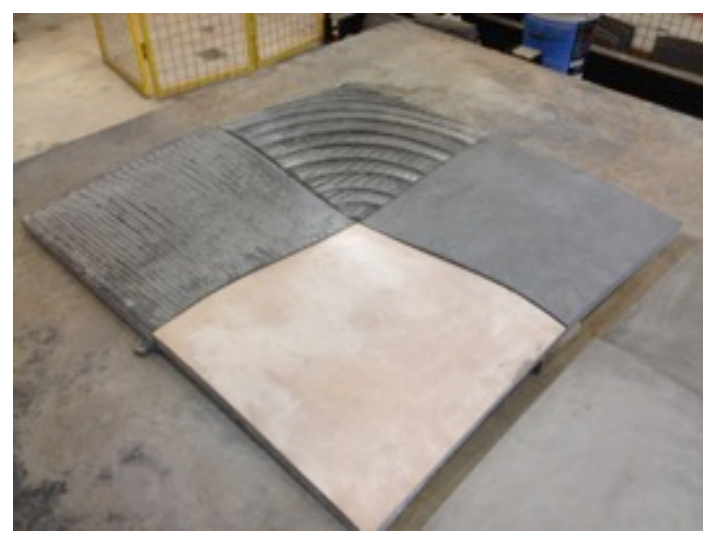

Figure 20: Doubly-curved panel printed with four different surface finishing (1m $(\mathrm{W}) \mathrm{x}$ $1 \mathrm{~m}(\mathrm{~L}) \times 0.03 \mathrm{~m}(\mathrm{H})$ ). The finishes include rendering with gypsum (bottom, bright colour), naturally controlled (top), extra printed radial pattern (right) and ground (left).

\section{Discussion}

The Grasshopper definition, developed to generate curved-layered printing paths from a given 3D model, showed several benefits compared with the first version we developed using Rhinoceros and Visual Basic. The Rhinoceros and Visual Basic version needs to extract the printing path coordinates from Rhinoceros, save it as a text file, and import it to a Visual Basic script for GCode conversion. Because we are dealing with life-scale construction objects, the printing operation needs to be split by layers, as the area of a layer would be large and the top surface of the printed layer could be hardened before the next layer's filament is deposited over the area. In this case, an additional bonding agent (in our case, water) needs to be applied on the surface before the next printing layer, to increase the bonding capability. Thus the extracted paths are saved layer by layer, which could be cumbersome if the printing object consists of many layers. The Grasshopper version minimises the effort, as all tasks are done within a single scripting environment. It can also easily generate alternative paths, adjusting only a few parameters in the Grasshopper definition instead of recreating paths from scratch, thereby minimising the gap between the design and the manufacturing (printing) process.

The flat and curved layer paths of the doubly-curved sandwich panel shown in Figure 2 were evaluated with regard to: (i) surface finishing quality, (ii) number of layers and printing time, and (iii) bonding between layers.

Firstly, the surface roughness and visual impact of both paths were simulated to see how the staircase effect using flat-layered paths differs from the natural profile strips using curved-layered paths. The panel with a flat-layered printing method (Figure 2a) shows variable shapes and sizes of layers similar to graphical contour lines. On the other hand, the panel with a curved-layered method (Figure $2 b$ ) has almost identical 
shapes and sizes of layers. Thus, it is clear that the curved-layered path dramatically improve the surface finishing quality.

Secondly, the number of layers and the printing time of the flat-layered and the curved-layered printing paths were compared through a simulation (Table 2). Note that the printing time in Table 2 includes non-printing traverse and dwelling-time for nozzle positioning etc., and the printing speeds of both the flat-layered and the curved-layered printing are set to $4,000 \mathrm{~mm}$ and $3,000 \mathrm{~mm}$ per minute respectively. The speed parameters were set for optimal extrusion of each method, i.e. consistent width and thickness of the extruded filaments. When a filament is deposited on a curved layer, the deposited filament is dragged harder than on a flat layer, which means it is stretched and become thinner than expected. Thus, the printing speed for the curved-layer path was reduced to minimise the effect.

The numbers of layers required show a remarkable difference: between 39 and 59 layers with the flat-layered path, and only 17 layers with the curved-layered path. Furthermore, despite the slower printing speed, the curved-layered path requires less than 17 hours in total while the flat-layered path requires about 23 hours, made possible by the shorter total traverse with fewer layers.

Table 2: Printing time and number of layers of flat- and curved-layered paths.

\begin{tabular}{|c|c|c|c|c|}
\hline & \multicolumn{2}{|c|}{$\begin{array}{l}\text { Flat-layered printing } \\
(4,000 \mathrm{~mm} / \mathrm{min})\end{array}$} & \multicolumn{2}{|c|}{$\begin{array}{c}\text { Curved-layered printing } \\
(3,000 \mathrm{~mm} / \mathrm{min})\end{array}$} \\
\hline & Layers & Printing time (sec) & Layers & Printing time (sec) \\
\hline $\begin{array}{l}1^{\text {st }} \text { panel } \\
\text { (Top left) }\end{array}$ & 54 & 21,162 (5h 52m 42s) & 17 & 14,695 (4h 04m 55s) \\
\hline $\begin{array}{l}2^{\text {nd }} \text { panel } \\
\text { (Top right) }\end{array}$ & 45 & 19,030 (5h 17m 10s) & 17 & 13,792 (3h 49m 52s) \\
\hline $\begin{array}{c}3^{\text {rd }} \text { panel } \\
\text { (Bottom left) }\end{array}$ & 39 & 18,285 (5h 04m 45s) & 17 & 15,321 (4h 15m 21s) \\
\hline $\begin{array}{c}4^{\text {th }} \text { panel } \\
\text { (Bottom right) }\end{array}$ & 50 & 19,822 (5h 30m 22s) & 17 & 16,294 (4h 31m 34s) \\
\hline $\begin{array}{c}\text { Print all } \\
\text { panels at once }\end{array}$ & 59 & 82,400 (22h 53m 20s) & 17 & 60,102 (16h 41m 42s) \\
\hline
\end{tabular}

Thirdly, the edges of the all layers with the flat-layered path are not matched and some layers are much smaller than other layers, e.g. those at the top are less than $5 \%$ of the first layer, thus they are prone to peeling off as a result of certain horizontal forces. On the other hand, the all layers with the curved-layered path share a same shape and size; thus each layer has maximum contact area with the next layers. Moreover, the curved-layered path required 17 layers only for each panel while the flat-layered path used between 39 and 59 layers for each panel. This means the curved-layered part is less vulnerable to poor adhesion between layers and hence promises greater structural integrity of the printed object by reducing the layers by over $70 \%$ of layers. We can infer this from our previous investigations [14] because the way each layer 'flows' into the layer below is critical to controlling the pore distribution of the printed mortar (and hence its density and compressive/tensile strength) and also the bond strength between the layers (as measured in tensile bond tests). Furthermore, both the mortar's rheology (which is a function of the time since mixing) and the nozzle speed influence the degree to which the upper layers flow to fill any voids initially formed during the encasement of the lower layers. A recent research on an adaptive slicing method [37] pointed out that increasing fine (i.e. thinner) layers would allow more strengths with less porosity although it will increase printing time when same printing methods (i.e. flat-layered path) are 
compared. In our experiment, we have compared two different methods, i.e. flat- and curved-layered path, which cause a structural difference influencing the bonding strengths between the components. Hence, in the case of comparison between flatlayered and curved-layered paths, fewer layers mean better mechanical properties because the filament continuity and the contact area between layers are increased while the anisotropic structure of bonded filaments is reduced. Therefore, we can make the inferences that more layers, faster printing (to compensate), longer total printing time (per mortar batch) and greater diversity of as-printed filament width will all increase the risks of greater porosity, lower strength and lower adhesion.

The question then arises as to the implications of such a layered printing process on full-scale concrete construction. Producing curved concrete products, whether off-site (precast) or in-situ, with traditional mould-casting techniques is an expensive, timeconsuming process, to the extent that with the exception of where multiple identical products are required in volume, it is rarely done. As with all additive fabrication methods there is a break-even point where the unit cost/number of parts relationship that is constant for AM matches the asymptotic relationship for mould-cast processes. Above that number of parts, mould casting is cheaper and below AM would be. However as commercial AM concrete construction doesn't yet exist, the production of geometrically complex, one-off components is avoided due to high mould costs, with some notable exceptions such as moulded sculptural installations and the use of sprayed concrete that avoids moulds but is generally not regarded as true AM in the sense of precisely controlled layer deposition.

The small numbers of concrete extrusion-based AM process that are public are very similar in printing flat layers stacked vertically so as to avoid overhang. Curved-layer printing offers the ability to produce complex geometrical parts without moulds, where the production time would be a fraction of that where each part needs the making of its own mould. Hence a process such as 3DCP offers significant potential in applications where such complexity is of value to the client, such as cladding panels.

\section{Conclusion}

This work demonstrates the innovation of CLFDM using curved-layered printing paths, which will be beneficial to a large-scale AM techniques in particular, by minimising the staircase effect on curved surfaces - one of the major weaknesses of the conventional flat-layered path. Grasshopper - a plugin of Rhinoceros - was successfully used to exploit the potential capability to generate curved-layered printing paths and convert them to GCode in a single scripting environment. The GCode produced was evaluated through the printing simulations and actual print examples (shown above) using the 3DCP system. As the above examples show, the surface printed with curved-layered paths is aesthetically pleasing and of higher quality than a surface created by a flat-layered path because it allows (i) better surface geometrical quality by minimising the staircase effect; (ii) shorter printing time by printing fewer layers, and hence (iii) better inter-filament bonding by minimising the voids and maximising the contact area between layers. The current concrete construction market avoids the production of parts with such complexity where the production numbers are low. The 3DCP system offers new opportunities to significantly decrease production times and hence costs.

\section{Acknowledgements}

The work outlined in this paper was funded by the EPSRC (grant EP/E002323/1 and an associated Knowledge Transfer Account grant) at Loughborough University. The authors gratefully acknowledge the technical contribution of John Webster in the 
development of the 3D Concrete Printing system. The authors also thank Buro Happold for their assistance in the structural analysis.

\section{References}

1. R. Hague, I. Campbell, P. Dickens, Implications on design of rapid manufacturing, Proceedings of the Institution of Mechanical Engineers, Part C: Journal of Mechanical Engineering Science, 217 (1) (2003) 25-30.

2. M.A. Evans, R.I. Campbell, A comparative evaluation of industrial design models produced using rapid prototyping and workshop-based fabrication techniques, Rapid Prototyping Journal, 9 (5) (2003) 344-351.

3. S. Sambu, Y. Chen, D.W. Rosen, Geometric tailoring: A design for manufacturing method for rapid prototyping and rapid tooling, Journal of Mechanical Design, 126 (4) (2004) 571-580.

4. B. Khoshnevis, D. Hwang, K. Yao, Z. Yeh, Mega-scale fabrication by contour crafting, International Journal of Industrial and System Engineering, 1 (3) (2006) 301-320.

5. E. Dini, Full-size Stone 3D Printing. in Smart Geometry 2010 Symposium, Barcelona, Spain, 23-24th March 2010.

6. S. Lim, R.A. Buswell, T.T. Le, S.A. Austin, A.G.F. Gibb, A. Thorpe, Developments in construction-scale additive manufacturing processes, Automation in Construction, 21 (1) (2012) 262-268.

7. N. Hopkinson, Y. Gao, D.J. McAfee, Design for environment analysis applied to rapid manufacturing, Proceedings of IMechE, Part D: Journal of Automobile Engineering, 220 (10) (2006) 1363-1372.

8. R.A. Buswell, R.C. Soar, A.G.F. Gibb, A. Thorpe, Freeform Construction: Megascale rapid manufacturing for construction, Automation in Construction, 16 (2) (2007) 224-231.

9. Foster+Partners. "Motor City, Aragon, Spain.", http://www.fosterandpartners.com/Projects/1518/Default.aspx

10. Foster+Partners. "UAE Pavilion Shanghai Expo 2008", http://www.fosterandpartners.com/Projects/1716/Default.aspx

11. Foster+Partners. "Masdar City Housing Development.", http://www.fosterandpartners.com/projects/masdar-development/

12. E. Sabourin, S.A. Houser, J.H. Bøhn, Adaptive slicing using stepwise uniform refinement, Rapid Prototyping Journal, 2 (4) (1996) 20-26.

13. C.S. Lee, S.G. Kim, H.J. Kim, S.H. Ahn, Measurement of anisotropic compressive strength of rapid prototyping parts, Journal of Material Processing Technology, 187-188 (2007) 627-630.

14. T.T. Le, S.A. Austin, S. Lim, R.A. Buswell, R. Law, A.G.F. Gibb, A. Thorpe, Hardened properties for high-performance printing concrete, Cement and Concrete Research Journal, 42 (3) (2012) 558-566.

15. H. Wenbin, L.Y. Tsui, G. Haiqing, A study of the staircase effect induced by material shrinkage in rapid prototyping, Rapid Prototyping Journal, 11 (2) (2005) 82-89.

16. G. Kalmanovich, L. Dodin, S. Tu, Curved-layer Laminated Object Manufacturing ${ }^{\circledR}$. in Proceedings of the 7th International Conference on Rapid Prototyping, University of Dayton and Stanford University, 31 March - 3 April 1997, pp. 51-59.

17. D.A. Klosterman, R.P. Chartoff, N.R. Osborne, G.A. Graves, A. Lightman, G. Han, A. Bezeredi, S. Rodrigues, Development of a curved layer LOM process for monolithic ceramics and ceramic matrix composites, Rapid Prototyping Journal, 5 (2) (1999) 61-67. 
18. S. Singamneni, O. Diegel, B. Huang, I. Gibson, R. Chowdhury, Curved Layer Fused Deposition Modeling, in Rapid Product Development Association of South Africa (RAPDASA), 9th Annual International Conference on Rapid Product Development. South Africa, 2008.

19. D. Chakraborty, B. Aneesh Reddy, A. RoyChoudhury, Extruder path generation for Curved Layer Fused Deposition Modeling, Computer-Aided Design, 40 (2) (2008) 235-243.

20. O. Diegel, S. Singamneni, B. Huang, I. Gibson, The future of electronic products: conductive 3D Printing? in 4th International Conference on Advanced Research in Virtual and Rapid Prototyping, Leiria, Portugal, September 2009.

21. B. Huang, Development of a software procedure for Curved Layered Fused Deposition Modelling (CLFDM), in School of Engineering, Auckland University of Technology, Auckland, New Zealand, 2009.

22. V. Anand, An Investigation into curved layer deposition for Fused Deposition Modelling, in School of Engineering, Auckland University of Technology, Auckland, New Zealand, 2010.

23. O. Diegel, S. Singamneni, B. Huang, I. Gibson, Curved Layer Fused Deposition Modelling in Conductive Polymer Additive Manufacturing, Advanced Materials Research, 199-200 (2011) 1984-1987.

24. B. Huang and S. Singamneni, Curved Layer Adaptive Slicing (CLAS) for fused deposition modelling, Rapid Prototyping Journal, 21 (4) (2015) 354-367.

25. A. Bellini, S. Güceri, Mechanical characterization of parts fabricated using fused deposition modeling, Rapid Prototyping Journal, 9 (4) (2003) 252-264.

26. G.D. Kim and Y.T. Oh, A benchmark study on rapid prototyping processes and machines: quantitative comparisons of mechanical properties, accuracy, roughness, speed, and material cost, Proceedings of the Institution of Mechanical Engineers, Part B: Journal of Engineering Manufacture, 222 (2) (2008) 201-215

27. R.J.A. Allen and R.S. Trask, An experimental demonstration of effective Curved Layer Fused Filament Fabrication utilising a parallel deposition robot, Additive Manufacturing, 8 (2015) 78-87.

28. McNeel. "Rhinoceros", http://www.rhino3d.com/

29. T.T. Le, S.A. Austin, S. Lim, R.A. Buswell, A.G.F. Gibb, A. Thorpe, Mix design and fresh properties for high-performance pritning concrete, RILEM Materials \& Structures, 45 (8) (2012) 1221-1232.

30. K. Park, N. Holt, Parametric Design Process of a Complex Building In Practice Using Programmed Code As Master Model, International Journal of Architectural Computing, 8 (3) (2010) 359-376.

31. M.L. Prete, L.D. Cerro, V. Bonora, CANOPÉE DES HALLES DE PARIS: Case study for an innovative digital approach to tender competition, in Proceedings of the CIB W78-W102 International Conference, Sophia Antipolis, France, 26-28 October 2011.

32. O. Kontovourkis, Design of circulation diagrams in macro-scale level based on human movement behavior modeling, Automation in Construction, 22 (2012) 1223.

33. McNeel. "Grasshopper: Generative modelling for Rhino.", http://www.grasshopper3d.com/

34. Autodesk. "Lesson 4: Using BIM for Fabrication.", http://bimcurriculum.autodesk.com/lesson/lesson-4-using-bim-fabrication

35. J. Mirtschin, "Geometry Gym BIM.", http://www.grasshopper3d.com/group/geometrygym

36. E. Harriss, S. Perez, CAMel: 5-axis GCode generator (Grasshopper plugin), http://maxwelldemon.com/2011/09/29/camel/ 
37. B. Huang and S. Singamneni, Adaptive slicing and speed- and time-dependent consolidation mechanisms in fused deposition modelling, Proceedings of IMechE, Part B: Journal of Engineering Manufacture, 228 (1) (2014) 111-126.

\section{Appendix 1}

For safe handling and movement, the load capacity of the panel piece was estimated through three types of structural analysis: (i) flange in bending; (ii) flange in shear; and (iii) the bond (in direct tension) between the flanges and a pillar (Figure A.1). The analysis indicated that the four bottom pillars need to be improved (Figure A.2), thus they are merged as a pair of flanges and the middle pillar is eliminated in the revised design.

1. Flange in bending: The worst-case scenario in bending might be the flange working as a cantilever element with the largest span $(L)$ of $60 \mathrm{~mm}$. the crack is assumed as a dot-line section $\left(A-A^{\prime}\right)$ shown in Figure A.1. The failure load $(P)$ can be calculated as below, and estimated failure load of a point load at the edge is $6,000 \mathrm{~N}$ (approx. $600 \mathrm{Kg}$ ), which means that a line load at the edge needs to be $600 \mathrm{Kg} / \mathrm{m}$ to fail the flange.

$$
\mathrm{P}=\frac{b \times d^{2}}{6 \times L} \times f_{\text {flex }}^{\text {characteristic }}=\frac{750 \times 24^{2}}{6 \times 60} \times 5=6,000 \mathrm{~N}
$$

where: $f_{\text {flex }}^{\text {characteristic }}$ is flexural strength (experimental results $5 \mathrm{~N} / \mathrm{mm}^{2}$ )

$b$ is the length of the panel, $b=750 \mathrm{~mm}$

$d$ is the thickness of the panel, $d=24 \mathrm{~mm}$

2. Flange in shear: The load capacity in shear of the flange is

$V_{\text {flange }}=f_{v} \times b \times d$

(Eq. 2)

where: $f_{v}$ is the shear strength of concrete, assumed $f_{v}=2.5 \mathrm{~N} / \mathrm{mm}^{2}$ based

on the above flexural strength, $f_{\text {flex }}^{\text {characteristic }}=5 \mathrm{~N} / \mathrm{mm}^{2}$

$b$ is the width of failure surface in shear $(\mathrm{mm})$

$d$ is the thickness of flange, $d=24 \mathrm{~mm}$

Thus, $V_{\text {flange }}=2.5 \times b \times 24=60 \times b(\mathrm{~N})$, which means that every $10 \mathrm{~mm}$ flange broken needs a load of $600 \mathrm{~N}$ (approx. $60 \mathrm{Kg}$ ). The worst-case scenario is a broken flange if the panel is handled at the corner as depicted by a dotted arc on the top-right side of the panel in Figure A.1, and the estimated failure load is $4,520 \mathrm{~N}$ (approx. $452 \mathrm{Kg}$ ). The failure load is

$$
1.5 \times P_{\text {failure }}=f_{v} \times b \times d
$$

where: 1.5 is the safety factor assumed

$b$ is the length of the crack, $b=113 \mathrm{~mm}$

Thus, $P_{\text {failure }}=(2.5 \times 113 \times 24) / 1.5=4,520 \mathrm{~N}$. 
3. The bond (in direct tension) between the flanges and a pillar: The failure load of the bond (in direct tension) between a flange and a pillar is estimated as $5,390 \mathrm{~N}$ (approx. $539 \mathrm{Kg}$ ). The bond capacity of a pillar and a flange is

$$
F_{\text {bond }}=f_{\text {bond }} \times A_{\text {pillar }}
$$

where: $f_{\text {bond }}$ is the bond strength of concrete, experimental result for 1 hour gap print $\left(1.1 \mathrm{~N} / \mathrm{mm}^{2}\right)$

$A_{\text {pillar }}$ is the cross section area of a pillar $\left(70 \times 70=4,900 \mathrm{~mm}^{2}\right)$

Thus, $F_{\text {bond }}=1.1 \times 4,900=5,390 \mathrm{~N}$.

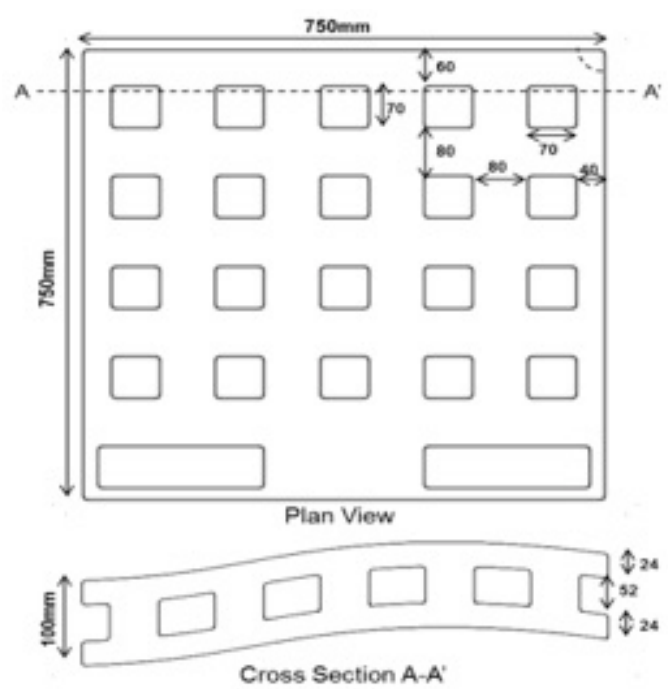

Figure A.1: Plan view and cross-section of the doubly-curved sandwich panel.
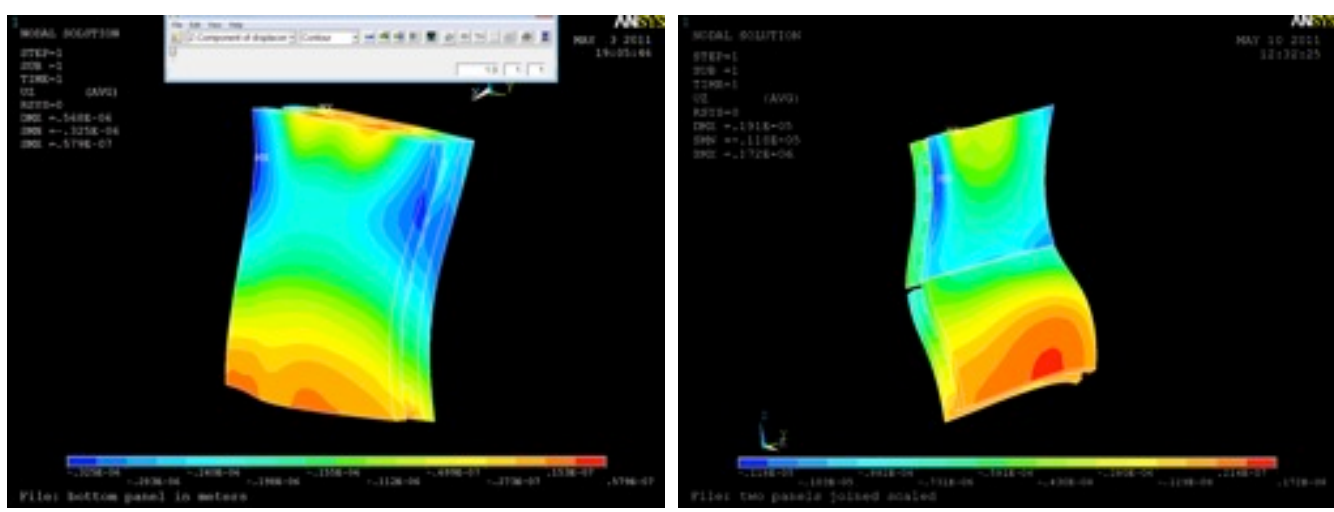

Figure A.2: Structural analysis of a sandwich panel (left) and two stacked panels shows the weakest part, thus the bottom four pillars are merged as two (right).

\section{Appendix 2}




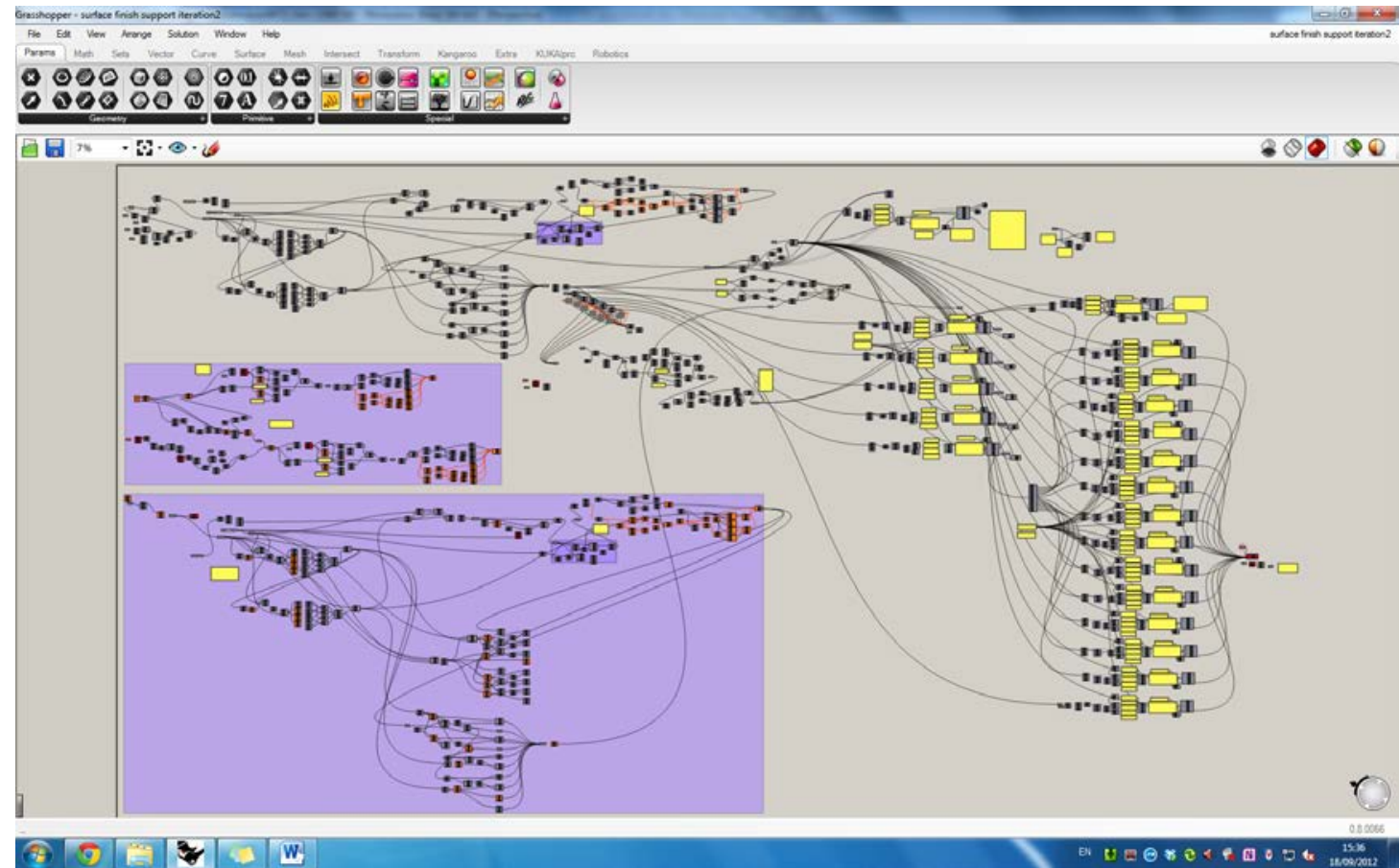

Figure A.3: Full grasshopper definition for the curved-layer path generation. 